\title{
Centones gongorinos en Nueva España
}

\section{Gongorian Centos in New Spain}

\author{
Martha Lilia Tenorio \\ El Colegio de México \\ Centro de Estudios Lingüisticos y Literarios \\ mtenorio@colmex.mx
}

\section{ResuMEN}

Los centones son un curioso subgénero literario, practicado desde la Antigüedad clásica. En Nueva España se compusieron centones virgilianos, sobre la Virgen de Guadalupe, y gongorinos, sobre la Inmaculada Concepción. Aquí se editan, con una breve introducción sobre este tipo de composiciones, los seis centones gongorinos que se compusieron en Nueva España.

\section{Palabras Clave}

Góngora, centón, Inmaculada Concepción, certámenes.

\section{AbSTRACT}

The poetic form known as cento, composed of sections or verses of other poems, represents a curious literary subgenre practiced since Classical times. In New Spain, we have examples of Virgilian centos, centos about Our Lady of Guadalupe, and Gongorian centos on the Immaculate Conception. This article contains both a brief introduction on this poetic form and the textual edition of the six Gongorian centos that were composed in New Spain.

\section{KEYWORDS}

Góngora, cento, Immaculate Conception, poetry contests.

RECEPCIÓN: 15/02/2019

ACEPTACIÓN: 05/04/2019

$\mathrm{E}$ n la introducción al tomo 2 de sus Poetas novohispanos. Segundo siglo (1621-1721), Méndez Plancarte habla de los centones compuestos en Nueva España con versos de Góngora o de Virgilio. Da noticia (y es lo que yo misma he podido encontrar) de seis centones gongorinos y seis virgilianos. Aquí edito los seis gongorinos, con algunas explicaciones y notas, así como con una breve introducción sobre el centón y su técnica. 


\section{El centón: definición y técnica}

El término cento proviene del griego kentron, 'aguja'. El Oxford Latin Dictionary lo define como "a garment of several bits or pieces sewed together", es decir, una pieza textil compuesta de varios retazos. De ahí, el término se desplazó semánticamente para significar composiciones formadas por fragmentos tomados de uno o más poetas. El género apareció por primera vez hacia el siglo III, floreció en la Antigüedad tardía, con alguna presencia en la Edad Media, cierta revitalización en el Renacimiento y muy ocasionales apariciones posteriores (por eso, precisamente, llaman la atención los centones novohispanos, casi todos del siglo XVII y algunos de comienzos del siglo XVIII). Los centones más famosos son los de la Antigüedad tardía, compuestos a partir de Homero o de Virgilio.

El manifiesto poético más importante y sistemático sobre la práctica centonaria es el "Prefacio" de Ausonio a su Cento Nuptialis: "Centonem vocant, qui primi hac concinnatione luserunt. Solae memoria negotium sparsa colligere et integrare lacerata, quos ridere magis quam laudare possis" (1999: 145-149). ${ }^{1}$ Un poco más adelante viene una detallada descripción de la técnica del centón: "Y si me permites que te enseñe - yo que debo ser enseñado- qué es un centón, lo haré. Con pasajes variados y sentidos diferentes se suelta una estructura de poema, de modo que estén unidos, en un solo verso, dos cortados o uno cortado y la mitad del siguiente con otra mitad. Pues colocar dos unidos es una torpeza, y tres de un tirón, una bobada completa."(Ausonio, 1990: 45).

La caracterización del centón como solae memoria negotium, "un asunto estrictamente de memoria", explica bien el lugar que esta forma literaria ocupa en la historia de la literatura clásica. El género requiere que tanto el escritor como el lector recuerden fragmentos poéticos desgajados de sus contextos originales; ejercicio que muestra la influencia de las prácticas pedagógicas que consistían en analizar laboriosamente pasajes de autores canónicos, análisis que promovía el uso de intertextos literarios en el discurso culto. El centón es la extensión lógica de esa práctica: la manipulación memoriosa de otros textos da cuenta de la manera en que éstos funcionaban como "pactos" entre los lectores que los entendían como fuentes de una lengua autorizada y que autorizaba.

El valor literario del centón estaba determinado por la literalidad con que se recrearan los versos de Virgilio o de Homero. De hecho, en el ya mencionado "Prefacio" a su Cento Nuptialis, Ausonio compara la composición de centones al juego conocido como "ostomaquia":2

1 'Los primeros que con esta manera de componer se divirtieron, la llaman 'centón'. Sólo es fruto de la memoria el recoger lo disperso y unir lo desunido; bien puedes reír más que elogiar esto" (tomo la traducción de Ausonio, 1990: 44).

${ }^{2}$ Explica A. Alvar Ezquerra que el término se traduce como "combate de huesos", "juego comparable a nuestro puzzle" (en Ausonio, 1990: 45). 


\section{Centones gongorinos en Nueva España}

Son unos huesecillos: en conjunto tienen catorce figuras geométricas [...] Con diferentes uniones de estas piezas se componen figuras de mil tipos: un elefante salvaje o un jabalí, un ganso volando y un mirmilón armado, un cazador emboscado y un perro ladrando, o bien una torre y un cántaro, y otras innumerables figuras de modo semejante, que varían si un jugador es más hábil que otro. Son asombrosas las combinaciones de los expertos; ridículas las uniones de los inexpertos (1990: 45-46).

No se trata, pues, de amontonar versos de diversas procedencias, sino de darles una forma nueva en relación con el modelo, una forma lógica, congruente. La habilidad tiene que trascender el aspecto meramente técnico. Se supone la confianza de un poeta (en este caso Ausonio) en la palabra de otro poeta (en el Cento ausoniano, Virgilio): en la capacidad intrínseca de la lengua y sus expresiones de ofrecer una ambivalencia de significado que permite que los pasajes tomados puedan remitir a situaciones sustancialmente diversas. ${ }^{3}$ Las dificultades a superar son muchas: "era preciso recoger fragmentos diversos, cortados por lugares predeterminados, que tuviesen sentido y concordancia gramatical entre ellos, y que las mutaciones semánticas, que los términos se ven obligados a sufrir para adaptarse a un nuevo sentido, no acusen violencia" (E. Montero Cartelle citado en Parra: 365). Esta "adaptación” implicaba muchas veces (aunque, teóricamente, no era lo deseable u ortodoxo) cierto tipo de alteraciones, por mínimas que fueran, gramaticales, semánticas, métricas, prosódicas, a veces léxicas.

Por estas características, para muchos estudiosos se trata de un género menor, un "esercizio scolastico inferiore" (Giorgio Pasquali citado en Lamacchia, 1996: 734), plagado de repeticiones, incongruencias léxicas, "suturas" audaces o poco lógicas, frecuentes alteraciones semánticas y anomalías prosódicas y métricas. Sin embargo, a partir de las ideas del propio G. Pasquali sobre el arte alusiva, de la noción moderna de "intertextualidad" o del muy sugerente análisis de Gian Biagio Conte sobre la función retórica y estilística de alusión (véase 1986 y 2017), se puede apreciar el valor de los centones por su capacidad de relectura literaria. La intertextualidad del centón es única, porque es absoluta y por el estrecho vínculo establecido con la fuente original. Ninguna otra forma literaria se compromete con algún autor, uno solo, tan evidente, persuasiva y exclusivamente.

Según explica Óscar Prieto Domínguez (15), el análisis de este género dio un giro cuando F. Desbordes entrevió su relación con la intertextualidad e hizo énfasis en que se trataba de un nuevo texto, puesto que "changer le contexte, c'est changer le texte" (Desbordes citado en Prieto: 15). A fin de cuentas, el centón se presenta como un texto nuevo que, aunque mezcla versos ajenos, los organiza de otra manera, preñando de sentido la nueva combinación o estructura, pues los contenidos no sólo son otros, sino

${ }^{3}$ El Cento Nuptialis, por ejemplo, usa los versos del "casto" Virgilio para contar la noche de bodas y el desfloramiento de una doncella. 
radicalmente distintos a los de los modelos originales. Esta operación de "robar" versos ajenos y de apelar a que el lector reconozca el robo y lo admire es, quizá, el núcleo estético del centón, pues, para que funcione, requiere que el lector capte las alusiones, reconociendo la obra de donde provienen y su contexto original: "necesita de un lector activo, capaz de desentrañar el interminable juego alusivo creado para poder construir así el significado último y verdadero del centón, el significado secundario oculto tras la erudición intertextual, que matiza, explica y, en parte, difiere del sentido lineal que obtenemos si nos limitamos a una mera lectura" (Prieto: 15).

En el centón, la literatura se produce, se recibe y muestra su andamiaje, sus principios de operación. Los lectores deben estar conscientes de la dualidad semántica del género: al desgajar versos de sus contextos originales y colocarlos en nuevos discursos, se provoca el mismo fenómeno que el uso de figuras estilísticas produce sobre la lengua de todos los días, cierto efecto de desfamiliarización que obliga al lector a poner atención en los cambios de significado operados en sus viejos y conocidos versos de siempre, a fijarse en ellos, de nuevo, negociando su significado en la constante vinculación con la fuente original: "The readers of the Latin centos are therefore expected to approach these 'verse jigsaw puzzle' with profound knowledge of Virgil's poetry; otherwise, they cannot relish the unique interplay of meanings, which contributes to the richness and complexity of the narratives told" (Okáčová: 4).

Evidentemente, condición para que se reconozcan las alusiones es la familiaridad con los modelos, de ahí la elección de poetas canónicos, aquellos cuyos versos llenaron la memoria poética y el imaginario de autores y lectores contemporáneos o posteriores, o porque se enseñaban en la escuela, o porque eran los más leídos, o por las dos cosas. Así, en la tradición centonaria sólo hay centones latinos, con versos de Virgilio, y griegos, a partir de Homero.

\section{Los centones cristianos}

En su origen, se componen, igual que los paganos, con versos de Homero y Virgilio, pero su argumento es cristiano, por lo que resultan muy diferentes en su inspiración, además de que tienen una finalidad claramente didáctica y de celebración doctrinal. No sólo es necesaria la complicidad literaria entre lector y autor, también la ideológica y devocional. Los poetas centonarios cristianos, además de usar versos conocidos por todos, articulan creencias compartidas por toda la comunidad para la cual escriben. La poesía de Homero o Virgilio, aunque ajena al mensaje cristiano, era la poesía heroica por excelencia, y por el momento de la historia del cristianismo en que los centones religiosos surgieron ( $c a$. siglo IV), "i più degni e i più idonei a celebrare l'epos cristiano e a edificare l'assemblea dei neofiti” (Lamacchia, 1996: 735). 


\section{Centones gongorinos en Nueva España}

Muy frecuentemente, la intención del centón pagano es la parodia-homenaje del modelo; esa distancia irónica está ausente en los centones cristianos: usan la tradición con seriedad y veneración para legitimar su mensaje. "Precisamente es esa seriedad lo que limita su capacidad alusiva al no remitir a la tradición de la que se apropia" (Prieto: 66). Óscar Prieto Domínguez piensa que la intención fuertemente doctrinal y didáctica impacta de manera negativa en la calidad literaria de estas composiciones, puesto que desaparece "el recurso a la complicidad pícara del lector" (66). Pareciera, entonces, que el contexto original no puede jugar, que el significado del centón no puede negociarse, como en los paganos, en la vinculación con el modelo. En mi opinión, la complicidad con el lector no desaparece: cambia de valencia, se hace más erudita y comprometida ideológicamente; el ejercicio intelectual que tiene que realizar el lector es más exigente, pues la operación de desfamiliarización de los versos clásicos resulta mucho más profunda. El lector no sólo debe haber interiorizado por completo los textos homéricos o virgilianos, no sólo debe ser capaz de reconocer y reconstruir los contextos originales, sino reconstruir, gracias a la devoción compartida, la operación alegórica que implica cargar con contenidos cristianos versos eminentemente paganos. Como dice muy bien Rosa Lamacchia, los centones cristianos son "esibizione in veste pagana di una dottrina cristiana, nella quale l'allusione si riduceva per lo più ad allegoria, e al giuoco si sostituiva la pietà" (1958: 216).

\section{Los centones gongorinos}

Es muy importante señalar la dignidad de clásico que se da a Góngora, en el mismo nivel que Homero y Virgilio: en español, prácticamente, sólo se hicieron centones a partir de versos de Góngora. ${ }^{4}$ La lengua del cordobés creó por sí misma una tradición discursiva: un conjunto de hábitos expresivos, de posibilidades y preferencias estilísticas; una memoria colectiva habitada por sus versos. Después de Virgilio, nadie más leído, más admirado, más venerado, más aprendido de memoria que Góngora.

Los primeros centones gongorinos se compusieron en España. Son tres: dos de Angulo y Pulgar, "Égloga fúnebre a don Luis" (1638) y "Elegía a doña Isabel de Borbón" (1644); un tercero, algo más tardío (1680) y posterior a los que presento aquí de Salazar y Torres y a los del certamen Empresa métrica, es el Epitalamio real a las bodas de

\footnotetext{
${ }^{4}$ Según Antonio Carreira, en toda la tradición hispánica sólo dos poetas merecieron los centones: Góngora y Virgilio (410). Gerardo Diego incluye también a Garcilaso: "que yo sepa, únicamente de Garcilaso y de Góngora se han hecho centones tejidos con sólo versos del poeta" (1927: 25). Jesús Ponce Cárdenas da noticias de un centón de versos de Garcilaso: Cristo Nuestro Señor en la cruz, hallado en los versos del príncipe de nuestros poetas, Garcilaso de la Vega, sacados de diferentes partes y unidos con ley de centones (Madrid, 1628), de Andosilla Larramendi (144).
} 
Carlos II, de Juan de Vera Tassis (véase Gallardo: col. 1023). Los otros seis centones gongorinos de los que tengo noticia se hicieron en Nueva España. ${ }^{5}$

Como en el caso de los centones latinos y griegos, los gongorinos se han visto como mero ejercicio escolar, de escaso valor literario. Por ejemplo, para Gerardo Diego: "Tales ejercicios no pueden reportar beneficio poético alguno, pero sí revelan una devoción a prueba de paciencia y en los casos o fragmentos más afortunados un alarde de ingenio" (2003: 72). A su vez, Méndez Plancarte sólo comenta: "son los centones la mayor pleitesía que una generación tan encendida de Góngora podía rendirle, como antaño a los máximos poetas [es decir, Homero y Virgilio]" (xx). No disiento de Gerardo Diego ni de Méndez Plancarte, pero, con esto, ¿ise ha explicado en realidad el fenómeno, particularmente novohispano, del centón gongorino? Además, algo debe significar que todas esas composiciones estén dedicadas al mismo tema, la Inmaculada Concepción. Como Virgilio fue el sostén de la épica guadalupana (en los centones), el conceptismo y la lírica gongorinos lo fueron de materia tan difícilmente asible: no hay que dejar de lado que seis centones son parte de certámenes dedicados al misterio mariano. La ecuación centón-Góngora-Inmaculada Concepción debe significar algo más que ejercicios o divertimentos sociales, académicos o literarios.

La Inmaculada Concepción fue declarada dogma el 8 de diciembre de 1854 por Pío IX, con la publicación de la bula Ineffabilis Deus. Así que en el siglo XVII era sólo una doctrina, no dogma; se valía aceptarla o rechazarla. Sin embargo, en el mundo hispánico-católico tuvo una efervescencia muy particular: "Fue el pueblo, esencialmente el pueblo, el que empujaba hacia adelante en su devoción de la Virgen María en su concepción inmaculada y el que obligaba a los teólogos a buscar vías de comprensión teológica de este misterio" (Ros: 13). La dificultad teológica es patente: ¿cómo compaginar la universalidad del pecado original, tan propugnada por san Pablo en sus cartas, y la redención de Jesucristo para toda criatura, con la concepción sin mancha de María?

Si la doctrina no podía defenderse con sólidas bases teológicas, sí podía celebrarse líricamente. De hecho, la Inmaculada Concepción tuvo gran importancia como motor del ingenio novohispano; por su indefinición y fragilidad teóricas, exigió a los poetas un trabajo alegórico y verbal digno de atención; de ahí los varios certámenes dedicados al tema.

El primer centón que presento es de Agustín de Salazar y Torres (1636-1675). Se encuentra en la Cíthara de Apolo. Primera parte (34-38), imitación de la Primera soledad, es

${ }^{5}$ Igualmente, hay que notar que el centón virgiliano cristiano "tomó un segundo aire" en suelo novohispano con seis composiciones: dos del último tercio del siglo XVII y cuatro de los primeros años del xVIII. Los dos del XVII relatan las apariciones de la Virgen de Guadalupe (fenómeno muy significativo: el epos virgiliano, la lengua épica por excelencia, es el vehículo para narrar el "epos mexicano"); los cuatro restantes están dentro del certamen Estatua de la paz (1724) a la coronación de Luis I. 


\section{Centones gongorinos en Nueva España}

decir, una silva (lo que aligera un poco el restrictivo marco del centón). Ya hablé del status de clásico en que se tenía a Góngora; al respecto, considero importante destacar dos hechos: uno, lo que cuenta el editor de Salazar y Torres, Juan de Vera Tassis, del joven poeta en la escuela:

en aquel sabio colegio de la Compañía de Jesús, teniendo aún menos de doze años de edad [en realidad, 18], después de aver recitado las Soledades y Polifemo de nuestro culto conceptuoso cordovés, fue comentando los más obscuros lugares, desatando las más intrincadas dudas y respondiendo a los más sutiles argumentos que le proponían los que muchos años se avían exercitado en su inteligencia y lectura (Salazar: f. 4r-4v).

El segundo, que la composición, como lo aclara el epígrafe, es trabajo de certamen. La exigencia de la justa le cayó a Salazar como anillo al dedo: ya se sabía de memoria la obra de Góngora. Asimismo, hay que señalar que no es éste su único poema sobre el tema mariano: en 1654, participó en el certamen a la Inmaculada Concepción, convocado por la Real y Pontificia Universidad de México (Certamen poético, 1654), y sus composiciones (un romance "de equívocos" y unas redondillas de pie quebrado) obtuvieron el segundo y primer lugares, respectivamente.

Los siguientes tres centones forman parte del certamen Empresa métrica (1665), convocado para la dedicación del templo de la Inmaculada por obra del virrey Héctor de Aragón. Están dentro de la tercera sección del certamen (ff. 16v-22r), cuyo asunto es:

Fue la diosa Vesta fecunda madre de las flores, y como a tal se le ofrecían [...] Pero María, siendo flor misteriosa que las exhala, no las pide para sí en sacrificio, ni a ella se le ofrecen en este templo: se porta tan generosa en su privilegio al verse obligada al Sol Jesús Nazareno, cuando en su presencia y a su influjo se ha avivado el fuego de la devoción, que tan apagado tenía el olvido en el antiguo [templo]; [...] hasta que la devota imagen de Jesús Nazareno encendió los corazones para su nueva dedicación, que, agradecida, no quiere que le toquen las flores, sino que a Jesús se toquen y surtan los milagros, que hemos visto aplicadas en las dolencias (f. 14v).

Sólo dos aclaraciones: 1) en 1524, Hernán Cortés mandó construir un hospital con la advocación de la Purísima Concepción, con una iglesia adyacente. El proyecto quedó inconcluso; se terminó hasta 1665 con la recepción de una imagen de Jesús Nazareno; por ello, la advocación del templo es doble: la Inmaculada y Jesús Nazareno; 2) el "privilegio" por el que la Virgen está agradecida es su exención del pecado original; el fraseo, fórmulas y presupuestos alegóricos en la narración del asunto resultan fundamentales para entender los centones.

Los últimos dos centones son parte de otro certamen a la Inmaculada, Triunfo parténico, convocado por la Real y Pontificia Universidad de México (1683). Por muchas razones, es éste uno de los certámenes más importantes de la Nueva España: por su 
secretario, Carlos de Sigüenza y Góngora, que se lució con las peripecias alegóricas para relacionar la épica de la Eneida con la Inmaculada Concepción; por la altísima participación (más de 500 poetas, según Sigüenza); por la suma de poesía y de poesía gongorina que representa; por la relevancia social de la patrocinadora (la Universidad), todo esto aunado al trend topic que era la doctrina mariana. Los centones forman parte de una de las secciones del Certamen IV. El asunto es el siguiente:

Reverente se acogió Eneas con toda su armada troyana a Delos, en donde halló quieta estación en lo abrigado de sus riberas [...] Y remunerando el dios sus piadosos cultos, le respondió en un oráculo que de su real estirpe vería fecunda propagación el ámbito de la tierra [...] Sabido es cuánto debió este misterio al austríaco Eneas monarca de dos mundos, el gran Filipo, ya afianzándolo en los corazones españoles con sus decretos, ya impetrando en su favor letras apostólicas para todo el universo católico, cuya ardiente devoción, navegando el golfo de su reinado, soltó las áncoras de su esperanza en el puerto seguro de María Inmaculada. Late esta misma en las augustas venas de nuestro católico rey y señor Carlos II (que Dios guarde), heredada juntamente con la monarquía. Y porque no deben menos estas religiosas demostraciones en culto del misterio al excelentísimo señor conde de Paredes, marqués de la Laguna, virrey y capitán general de esta Nueva España, se volverá el mismo oráculo de gentil en cristiano, celebrando la devoción de su Excelencia, y asegurando en el patrocinio de la Virgen purísima gloriosa sucesión... (ff. 72r-75r).

Algunas aclaraciones contextuales: 1) el "gran Filipo" es Felipe IV, padre de Carlos II, los dos grandes defensores de la Inmaculada Concepción; 2) la petición de descendencia para los virreyes se refiere al hecho de que la virreina había tenido dos abortos; Sigüenza, pues, le desea que pronto nazca el añorado heredero.

En cuanto al sustento poético y alegórico, las noticias provienen del lib. 3 de la Eneida: Eneas se refugia en Delos, isla que "depara a los cansados la más plácida acogida en su puerto seguro" (Virgilio: v. 78). Eneas va a orar al templo de Apolo Timbreo (deidad venerada en Delos) y escucha el siguiente oráculo: "Sufridos descendientes de Dárdano, la tierra primera en ver brotar la estirpe de vuestros ascendientes será la que os acoja en su fecundo seno a vuestra vuelta. Id a buscar a vuestra antigua madre. Allí el solar de Eneas ha de señorear el orbe entero, lo mismo que los hijos de sus hijos y los que de sus hijos nacerán" (v. 78). Un poco enrevesada, la alegoría propuesta por Sigüenza y Góngora es: Carlos II como nuevo Eneas, quien, con su imperio sobre el Nuevo Mundo, heredado de Felipe IV, expande el reino y la descendencia de españoles y católicos, gracias al oráculo, esto es, a su muy especial devoción a la Inmaculada Concepción (la Virgen es Delos; Apolo, Cristo).

Con este asunto debía elaborarse, entre otros metros, una canción a imitación de la gongorina En roscas de cristal serpiente breve, que se ha de componer "de centones, sacados precisamente del mismo don Luis de Góngora. Y se advierte a los poetas ser indispensable y expresa ley el que no sólo no se han de tomar dos, ni tres versos, 


\section{Centones gongorinos en Nueva España}

pero ni aun uno entero para subrogarlo en la canción" (Triunfo: f. 75r). Esto es, la composición exigida es una "gongorinada" exponencial: imitar la canción "En roscas de cristal serpiente breve...": cuatro estancias de diecisiete versos cada una, con un solo heptasílabo al centro, con rima ABCBACCdDEFFGGEHH, más una represa de cinco. La canción debe ser, además, un centón de versos de Góngora. El ejercicio resulta mucho más difícil que el requerido en Empresa métrica, pues, como se vio, ahí se trataba de silvas, metro que ofrece bastantes libertades.

\section{Mini-advertencia editorial}

Modernizo ortografía, puntuación y acentuación. En el caso de los centones de la Empresa métrica y del Triunfo parténico, los autores indican al margen la procedencia de los versos. Según mi revisión bibliográfica, usan la edición de Gonzalo de Hoces en la reimpresión de 1654 (Madrid, Imprenta Real). En cursivas marco las referencias originales, a las que añado, entre corchetes y en redondas, si el folio es recto o vuelto, o corrijo el número de folio cuando hay error. De igual manera, señalo el número al que corresponden esas referencias en las Obras completas de Góngora (edición de Antonio Carreira, 2000) y el número de versos en el caso de poemas extensos. Asimismo, de esta edición provienen todas las referencias a versos del autor cordobés. 



\title{
Centones gongorinos en Nueva España
}

\section{Centones}

1

Describe la visión del capítulo doce del Apocalipsis, con sólo versos mayores de don Luis de Góngora, siguiendo el método de sus Soledades. ${ }^{1}$

Fue asunto de un certamen de la Purísima Concepción de Nuestra Señora

\author{
Si arrebatado merecí algún día \\ tu dictamen, Euterpe, ${ }^{2}$ soberano, \\ solicitando en vano \\ las alas sepultar de mi osadía, \\ 5 audaz mi pensamiento \\ su canora dará dulce instrumento, \\ son de la ninfa un tiempo, ahora caña, ${ }^{3}$ \\ si ya la erudición no nos engaña: \\ émula de las trompas su armonía, \\ 10 el séptimo Trïón de nieves cano; ${ }^{5}$ \\ el rico de rüinas Océano; \\ la adusta Libia sorda aún más lo sienta \\ que los áspides fríos que alimenta. \\ Adonde luz de lumbre misteriosa* \\ 15 campos ilustra del Olimpo ardiente, ${ }^{6}$
}

[Panegírico, vv. 1-2]

[Sol. II, vv. 148-149]

[Sol. II, v. 137]

[D., Sol., v. 36]

[Sol. II, v. 831]

[Sol. II, v. 172] ${ }^{4}$

[Panegírico, vv. 5-6]

[72, v. 30]

[Panegírico, vv. 7-8]

[Romances varios]

${ }^{1}$ La teología mariana ha usado como fundamento para documentar los dogmas de la Inmaculada y de la Asunción la visión de san Juan en el capítulo 12:1 del Apocalipsis: "Y apareció en el cielo una señal grande, una mujer envuelta en el sol, con la luna debajo de sus pies, y sobre la cabeza una corona de doce estrellas". Esta mujer lucha con el dragón (el demonio) y lo vence; de ahí que la Virgen María haya nacido exenta del pecado original (dogma de la Inmaculada Concepción) y haya subido al cielo en cuerpo y alma, sin corrupción corporal (dogma de la Asunción). El "método de las Soledades" alude, simplemente, al metro: la silva.

${ }^{2}$ Euterpe: según la Teogonía de Hesíodo, es la musa de la flauta, por extensión, de la poesía bucólica. Góngora comienza así su Panegírico al duque de Lerma, pidiendo a Euterpe que inspire su lira: "bese el corvo marfil hoy de esta mía,/ sonante lira..."; es decir, la Euterpe gongorina funciona más como musa de la poesía elevada, sublime. Es el mismo aliento que recupera Salazar y Torres.

${ }^{3}$ Se trata de Siringe, hamadríade de Arcadia, amada por Pan. El dios la persiguió y, cuando iba a alcanzarla, Siringe se transformó en caña, de la que Pan formó la flauta.

${ }^{4}$ El verso está recompuesto, la cita no es textual: "no es sordo el mar (la erudición engaña)".

${ }^{5}$ El Septentrión, el norte, la zona más fría de la tierra (frente a la ardiente — "adusta"Libia). Son muy comunes en Góngora este tipo de perífrasis geográficas con hipérbole que significan que el canto del poeta se oirá de un lado a otro del mundo.

${ }^{6}$ Este verso no está tomado de Góngora, pero sí inspirado, quizá, en "Su nombre, aun de mayor aliento dino/ que en los clarines de la Fama cabe, / el campo ilustra de ese mármol grave" (núm. 269 de la ya citada edición de Antonio Carreira, vv. 5-7). Pongo asterisco en los versos 
viste el aire la púrpura del día. ${ }^{7}$

$[310$, v. 16$]$

$\mathrm{Al}$ sol sus arreboles, ${ }^{* 8}$

[f. $144 \mathrm{v}$ ]

Virgen tan bella, que hacer podía

[sic]

tórrida la Noruega con dos soles;

[Sol. I, vv. 783-784]

20 divinos ojos que en su dulce oriente dan luz al mundo, quitan luz al cielo;

hoy a sus rayos corre Amor el velo,*

matutinos del sol rayos vestida:

[Sol. I, v. 949]

ciñó sus sienes bellas

25 de antárticas estrellas.

[Sol. I, v. 429]

Juraré que lució más su guirnalda,

término puesto al oro y a la nieve, ${ }^{9}$

que la que ilustra el cielo en luces nueve; ${ }^{10}$

$[15$, v. $12,11,14]$

purpúreo son trofeo

30 de sus mejillas siempre vergonzosas ${ }^{11}$

bordadura de perlas sobre grana,

como suele, al romper la mañana,

aljófar blanco sobre blancas rosas;

claveles del abril Amor desata

[Sol. I, w. 791 y 790]

Sol. I, v. 786] $]^{13}$

que actualmente quedaron fuera del corpus gongorino, pero que estaban en las ediciones antiguas.

${ }^{7}$ Se refiere al oriente, donde nace el día. El verso gongorino dice: "viste al aire la púrpura del día"; "al aire" es circunstancial de lugar de un "viste", cuyo sujeto es María. Aquí, "el aire" es el sujeto de "viste".

${ }^{8}$ El verso es de Salazar y Torres, inspirado en "Ven, Himeneo, donde, entre arreboles/ de honesto rosicler, previene el día/ (aurora de sus ojos soberanos)/ virgen tan bella que hacer podría/ tórrida la Noruega con dos soles..." (Sol. I, vv. 780-784); como puede verse, el mismo pasaje de donde están extraídos los vv. 18-19 del centón.

${ }^{9}$ Esto es, como la guirnalda ciñe el rostro y la cabeza de la Virgen, sirve como "término", límite, orilla, al oro del cabello y la nieve de la tez. Típicos tópicos petrarquistas para describir la belleza femenina: el cabello oro, por el color y el brillo; la piel nieve, por la blancura. De hecho, a partir de estos versos comienza un muy artificioso retrato de la mujer apocalíptica (la Virgen María), con todas las galas, muy barroquizadas, del retrato petrarquista.

${ }^{10}$ Alusión a la diadema de oro, regalo de Vulcano, de Ariadna, convertida en constelación de nueve estrellas.

11 "siempre vergonzosas": porque, como doncella pudorosa, sus mejillas se sonrosan y están siempre rosadas.

12 "como suele, al romper la mañana": el soneto gongorino dice "Cual parece al romper la mañana".

${ }^{13}$ Este verso combina dos citas gongorinas. Como señalo, "claveles del abril" proviene del v. 786 de la Sol. I: "claveles del abril, rubíes tempranos"; mientras que la idea del Amor que "desata" ('disuelve') viene del Polifemo: "En lo viril desata de su vulto/ lo más dulce el Amor de su veneno" (vv. 285-286). 


\section{Centones gongorinos en Nueva España}

35 de su rostro, la nieve y escarlata, alto de Amor dulcísimo decoro, ${ }^{*}$ gloria mayor del soberano coro, ${ }^{*}$ de pura honestidad templo sagrado, cuyo bello cimiento y gentil muro,

40 de blando nácar y alabastro duro, fue por divina mano fabricado; sus espaldas rayando el sutil oro, ${ }^{15}$ beldad parlera, gracia muda ostenta, cual del rizado verde botón, donde

45 abrevia su hermosura Virgen rosa, padre de la que en sí bella se esconde, digna la juzga Esposa.

[Sol. I, vv. 726-728]

[Sol. I, v. 724]

[Sol. I, v. 732]

En hombros, pues, querúbicos, María,*

deidad resplandeciente,

50 levanta aquel León fiero ${ }^{16}$

del tribu ${ }^{17}$ de Judá, que honró el Madero:

donde al pie de la Virgen una a una*

hueste alada son cercos de la luna,*

cuyos altos no le era concedido

55 al serafín pisar, más levantado,

envidioso aun antes que vencido,*

en bordadura pretendió tan bella

poco rubí ser más que mucha estrella,

y, cuando no, admirado, ${ }^{18}$

60 se esconde, cual serpiente

en roja sangre y en ponzoña fría,*

pisando la dudosa luz del día.

Tarde batiste la envidiosa pluma,

de cuyo vuelo osado
[310, vv. 51-52]

[310, vv. 55-56]

$[103$, v. 79$]$

$[103$, v. 4$]$

[Polifemo, v. 72]
$[119$, v. 28]

\footnotetext{
${ }^{14}$ En el verso 40, hay una variante (¿errata?) con respecto al original: "de blanco nácar y alabastro duro". Podría ser sólo una errata en la edición de la Cýthara de Apolo, porque el adjetivo obligatorio en la lírica petrarquista para el nácar es blanco. Se entiende que el cambio haya pasado desapercibido, porque también es congruente el juego "blando nácar/ alabastro duro".

${ }^{15}$ Es decir, el rubio pelo suelto, a la espalda, como rayándola con sutiles hilos de oro (los mechones).

${ }^{16}$ Este "León fiero" es Cristo, como se aclara en el verso siguiente. En Apocalipsis, 12:3-4, se dice que la mujer parió un varón "que ha de apacentar a todas las naciones con vara de hierro"; es decir, el Salvador que venció el mal y redimió a la humanidad.

17 "del tribu": el Diccionario de Autoridades (en adelante, Dicc. Aut.) da este sustantivo como femenino o masculino, indistintamente.

18 "admirado": espantado.
} 
65 observarán su desvanecimiento ${ }^{19}$

los anales diáfanos del viento.

[Sol. II, vv. 142-143]

¡Oh ponzoñosa víbora escondida

de verde prado en oloroso seno,

[Sol. I, v. 114]

esfinge bachillera

[Sol. II, v. 320]

70 y sierpe, al fin, pisada!

[273, v. 54]

¡Oh pájaro de averno,

mayor debes de ser que el mismo infierno!

Pues comes de ti mismo y no te acabas, vuélvete al lugar triste donde estabas.

$[23, \text { vv. } 14,13 \text { y } 10]^{20}$

75 El rojo paso de la blanca Aurora,

de una alba que crepúsculos ignora,

tu cerviz pisa, dura,

yugo te pone de cristal, calzada

coturnos de oro el pie, armiños vestida.

80 Venza a la blanca nieve su blancura:

¡oh Virgen, oh siempre glorïosa!

$[310$, v. 65$]$

Donde el sol muere o donde nace el día,

ilustre y hermosísima María,

[Sol. II, v. 150 $]^{21}$

templo de quien el Sol aun no es estrella,

[293, v. 32]

85 aun a pesar de las tinieblas bella,

aun a pesar de las estrellas clara,

hoy de Moisés la vara*

los márgenes matiza de las fuentes,

serafines volantes y obedientes, ${ }^{*}$

90 en quien la Virgen estampó sus huellas,*

llegad $^{22}$ al cielo vuestras sacras frentes, ${ }^{*}$

que, eternizadas en sus luces bellas, ${ }^{*}$

estampas usurpáis a las estrellas.*

[Sol. I, w. 171-172]

[Sol. I, v. 618]

Pan.f. 181r

Can.f. $42 \mathrm{r}$

2

Primer lugar

del bachiller Juan de Guevara

Si arrebatado merecí algún día

de las Ninfas el coro y su concento, ${ }^{23}$

[Panegíicico, v. 1]

$[165$, v. 40$]$

${ }^{19}$ El verso de Góngora dice: “conservarán el desvanecimiento” (Sol. II, v. 142).

${ }^{20}$ Altera el v. 13 del soneto: "que comes de ti mesmo y no te acabas".

${ }^{21}$ El verso original tiene otro orden en los verbos: "donde el sol nace o donde muere el día".

22 llegar: "significa también arrimar o acercar alguna cosa hacia otra" (Dicc. Aut.). Esto es: 'serafines, acercad vuestras frentes al cielo donde está María'.

${ }^{23}$ concento: canto armonioso. 
Pan.f. 182r

Ded.f. $154 \mathrm{v}$

Ibidem

Son.f. 38 [33r]

Ibid. f. $48 \mathrm{v}$

Son. f. $9 \mathrm{r}$

Ibidem

Oct.f. $145 \mathrm{v}$

Sol.f. 166 [164v]

Sol.f. $164 \mathrm{v}$

Son.f. $13 \mathrm{v}$

Son.f. $10 \mathrm{r}$

Son.f. 22 [12r]

Ibidem $[12 \mathrm{r}]$

Son.f. $11[12 \mathrm{r}]$

Son.f. 22 [11r]

Son.f. 11 [9r]

Son. f. $12 \mathrm{r}$

Son.f. $3 \mathrm{v}$

Son.f. $22 \mathrm{r}$

Pol.f. 152r émulas de las trompas su armonía, su canoro dará dulce instrumento, ${ }^{24}$

5

cuando la Fama no, su trompa al viento. ${ }^{25}$

Fecunda Madre bella,

templo de quien el sol aun no es estrella,

divinos ojos que, en su claro oriente,

dan luz al mundo, quitan luz al cielo,

10 hoy que a sus rayos corre amor el velo. ${ }^{26}$

Virgen tan bella, que hacer podía $[s i c],{ }^{27}$

de sus mejillas siempre vergonzosas,

aljófar blanco sobre blancas rosas.

Ilustre y hermosísima María,

15 juraré que lució más su guirnalda, término puesto al oro y a la nieve, ${ }^{28}$

que la que ilustra el cielo en luces nueve, ${ }^{29}$

las rubias trenzas y la vista bella,

delante quien el sol es una estrella,

20 ondeábale el viento que corría:

corona de diamante, honor del día,

luces brillando aquél, éste, centellas,

¡oh tú, que en dos incluyes las más bellas! ${ }^{30}$
[Panegírico, v. 5]

[D., v. 36]

[D., v. 37]

$[293$, v. 52$]$

[174]

[Sol. I, v. 783]

[Sol. I, v. 790]

[Polifemo, v. 368]

${ }^{24}$ dará: concordancia ad sensum: el coro y el concento de las Ninfas darán...

${ }^{25}$ Estos primeros cinco versos constituyen la tópica petición de inspiración. Pueden parafrasearse así: 'Si, estando arrebatado [por la inspiración], algún día merecí el coro y el concento de las Ninfas, cuya armonía es émula de las trompas [trompetas de la Fama], ese coro [me] dará su dulce canoro instrumento, si no es que la Fama [dará] su trompa al viento'.

26 'Fecunda Madre bella [la Virgen María], templo tan resplandeciente ante el que, incluso el sol, no brillará ni como estrella: hoy que a los rayos del sol corre amor el velo, [se muestran] tus divinos ojos, desde cuyo claro oriente [lugar por donde sale el sol] dan luz al mundo, quitan luz al cielo'. "Templo" funciona como dilogía: María es templo de Cristo en tanto que lo encarnó; pero también se alude al templo de la Concepción que mandó construir Hernán Cortés en 1585, cuya edificación se terminó 80 años después, en 1665. Precisamente a la conclusión y dedicación de este templo está destinado el certamen.

${ }^{27}$ El verso gongorino dice "virgen tan bella, que hacer podría...".

${ }^{28}$ Recuérdese la representación apocalíptica (cap. 12) de la Virgen. Lo que dicen estos versos, sirviéndose de los topos petrarquistas del retrato femenino, es que la guirnalda que corona la cabeza de María sirve de término ('límite') al oro de su cabello y la nieve ('blancura') de su rostro.

${ }^{29}$ Véase supra, nota 10.

${ }^{30}$ vv. 20-23: 'El viento que corría le ondeaba sus rubias trenzas, frente a las cuales y frente a su vista bella, el sol es apenas una estrella. Esta guirnalda de luz es una corona de diamante y honor del día: el diamante brillando luces; el día, centellas'. Este cuadro de la luz que representa a María cierra, muy gongorinamente, con el epifonema “ $\mathrm{OOh}$ tú, que en dos incluyes las bellas!”, esto es, ‘ $\mathrm{O}$ h tú, María, que en dos luces [tus ojos] incluyes las más bellas [la luz de su belleza y la de su pureza]'. 
Son.f. $23 \mathrm{r}$

Son.f. $5 \mathrm{r}$

Pol.f. $150 \mathrm{v}$

Son.f. $34 \mathrm{v}$

Ibidem

Son. f. 3

Sol.f. $165 \mathrm{r}$

Son. f. $12 \mathrm{r}$

Son.f. 26v

Sol.f. $162 \mathrm{r}$

Ibidem

Pan.f. $187 \mathrm{r}$

Ibidem

Pan. f. $187 \mathrm{v}$

Ibidem

Can.f. $43 \mathrm{r}$

Ibidem

D. . $154 \mathrm{v}$

Son.f. $2 \mathrm{v}$

Sol.f. $150 \mathrm{r}$

Ibidem

Son. f. $2 \mathrm{r}$

Ibidem

Sol.f. $162 \mathrm{v}$

Ibidem

Sol.f. $171 \mathrm{v}$

Ibidem

Son.f. $13 \mathrm{r}$
Brillante siempre luz de un Sol eterno,

25 con rayos dulces mil de un Sol templado, ${ }^{31}$

mira la ofrenda ya con más cuidado,

de honor de majestad, de gallardía,

que privilegia el Sol y dora el día: ${ }^{2}$

[Polifemo, v. 242]
$[50]$

alto de amor dulcísimo decoro,

30 gloria mayor del soberano coro,

[Sol. I, v. 809]

que el cielo pinta de cien mil colores,

[Sol. I, v. 574]

[Sol. I, v. 575]

35 luminosos milagros hizo en cuanto

mudas lenguas en fuego llovió tanto,

[Panegírico, v. 390]

[Panegírico, v. 492]

[Panegírico, v. 526]

que ámbito a la tierra el mundo ejemplo, ${ }^{3.3}$

[Panegírico, v. 528]

al desengaño le fabrica templo.

[256]

40 del español Atlante,

$[D .$, v. 24$]$

[174]

[Sol. I, v. 97]

[Sol. I, v. 100]

[179]

[Sol. I, v. 630]

[Sol. I, v. 674]

[Sol. II, v. 79]

[Sol. II, v. 80]

[13]

${ }^{31}$ El "Sol" de los vv. 24-25 alude a Cristo, el "Sol" que habitó a María. Estos dos versos son el vocativo de "mira": "Virgen María, tú que eres brillante luz de un sol eterno..., mira con más cuidado nuestra ofrenda de honor, majestad y gallardía'.

${ }^{32}$ Este verso es una aposición de la "brillante luz" del v. 24, es decir, de María, y es la primera alusión al tema del centón, la Inmaculada Concepción: María fue privilegiada por el Sol, en tanto que, como madre de Cristo, fue liberada del pecado original.

33 "Que ámbito a la tierra, mudo ejemplo" (Panegírico, v. 526).

${ }^{34}$ sanefa: cenefa.

${ }^{35}$ El "Príncipe glorioso" es el virrey contemporáneo de Guevara, a quien se debe la conclusión y dedicación del templo: Héctor de Aragón, como Hernán Cortés, marqués del Valle.

${ }^{36}$ vv. 39-51: descripción "arquitectónica" del templo dedicado a la Inmaculada Concepción. Como es característico del centón, falla un poco la lógica: el verso "viendo pues que igualmente les quedaba", no encaja del todo. Al parecer, lo único que el poeta centonario está explotando de ese verso es el verbo "viendo", quienes están "viendo" son, creo, "triunfo y palmas", que "despertarán" ante la visión de tan maravilloso templo. 
Son.f. $4 \mathrm{r}$

Son.f. 44 [2r]

Son.f. $4 \mathrm{r}$

Son. f. $2 r$

Ibidem

Pol.f. $147 \mathrm{v}$

[Son.f. 16r]

Pol.f. $147 \mathrm{v}$

Ibidem

Sol.f. 166 [Son. f. 3v]

Ibidem [Son. f. 3v]

Sol.f. 166r

Sol.f. $155 \mathrm{r}$

Pol.f. 151v

Ibidem

Sol.f. 156 [150r]

Ibidem

Sol.f. $178 \mathrm{r}$

Son.f. $178 \mathrm{v}$

Sol.f. 160 [167r]

Ibidem [166v]

Sol.f. $179 \mathrm{v}$
Alta esperanza, gloria del estado, tu casa esclarecida,

55 cante Apolo de rayos coronado, no humilde musa de laurel ceñida: que si la mía puede ofrecer tanto, sin envidiar tu noble patria a Manto, ${ }^{38}$

[Polifemo, v. 22] clarín, y de la Fama no segundo,

60 tu nombre oirán los términos del mundo. ${ }^{39}$

Moderador del freno mexicano ${ }^{40}$ que en su tiempo, cerrado el templo a Jano, ${ }^{41}$

terno de gracias bello repetido

halló hospitalidad donde halló nido, ${ }^{42}$

65 y verdes celosías unas hiedras, trepando muros y abrazando piedras, borró designios, bosquejó modelos, al cóncavo ajustando de los cielos, y al de plumas vestido mexicano,

70 de esclarecido y aun de soberano, feroz ardiente muestra olímpica palestra que, a las estrellas hoy del firmamento,
[Polifemo, 24]

[Sol. I, v. 888]

[Sol. I, v. 27]

[Polifemo, v. 311]

[Polifemo, 312]

[Sol. I, v. 98]

[Sol. I, v. 99]

[Sol. II, v. 780]

[Sol. II, v. 821]

[Sol. I, v. 964]

[Sol. I, 961]

[Sol. II, v. 899]
[Polifemo, v. 23]

${ }^{37}$ Héctor de Aragón es segundo marqués del Valle, de ahí el "dos veces claro".

${ }^{38}$ Manto: Mantua, la patria de Virgilio, metonimia por el poeta latino. Aquí, o hay un error tipográfico o el bachiller Juan de Guevara no supo ni por dónde cantó el gallo. El verso está mal reproducido (yo corregí): "sin embidiar su noble patria amanto", que no tiene ningún sentido; además, falta la referencia. El verso proviene del soneto a Juan Rufo, jurado de Córdoba. La idea en el texto gongorino es la misma, sólo que en alabanza a Juan Rufo: tu musa no tiene nada que envidiar a Virgilio. Lo que Guevara parece decir es que si su musa se inspira, la patria del marqués no tendrá nada que envidiar a Mantua, pues el marqués (gracias al poema de Guevara) será tan reconocido como Virgilio. Como se ve, la alabanza acaba siendo, más que para el virrey, para el propio Guevara.

${ }^{39}$ vv. 52-60: 'Que sea Apolo, coronado de rayos, y no la humilde musa de laurel ceñida [esto es, la del poeta] quien cante, clarísimo marqués [el virrey, marqués del Valle], la alta esperanza, la gloria del estado que es tu casa esclarecida; pues, si acaso, mi musa puede ofrecer, sin que tu patria tenga que envidiar a Manto [Mantua la patria de Virgilio], un clarín tan grande como el de la Fama, tu nombre se oirá en todo el mundo'.

${ }^{40} \mathrm{El}$ virrey es un gobernador justo y apacible de los mexicanos.

${ }^{41}$ El templo de Jano se abría en tiempos de guerra y se cerraba en tiempos de paz. Esta alusión se debe a que el primer marqués del Valle, Hernán Cortés, gobernó en tiempos de guerra, y este otro marqués del Valle, el virrey Héctor de Aragón, en tiempos de paz.

42 "El terno de gracias bello repetido" son las tres gracias de Venus, cifradas en la gracia única de la Virgen María, quien halló templo en la nueva construcción. 


\begin{tabular}{|c|c|c|c|}
\hline Sol.f. $177 \mathrm{r}$ & & con la cumbre modesta, & [Sol. II, v. 691] \\
\hline Ibidem & 75 & por ser culta floresta, & [Sol. II, v. 694] \\
\hline Son. f. $137 \mathrm{r}$ & & fue su casa un devoto encerramiento & [433] \\
\hline Sol.f. $177 \mathrm{r}$ & & que, por su edad majestuosa, cano, & [Sol. II, v. 697] \\
\hline Ibidem & & antiguo descubrieron muro, ${ }^{43}$ & [Sol. II, v. 695] \\
\hline Solf. 177r & & mármol, en fin, tan por lo pario puro, & [Sol. II, v. 697] \\
\hline Pan.f. $16[187 \mathrm{v}]$ & 80 & que el adelantamiento a su victoria & [Panegírico, v. 544] \\
\hline Son.f. 23 & & en templo bien colgado y claustro rico, ${ }^{*}$ & \\
\hline Sol.f. 164 [Son. f. 16r] & & no hay paso concedido a mayor gloria. & [449] \\
\hline Son. f. $12 \mathrm{v}$ & & Bellísima es aquella fortaleza, & [99] \\
\hline Ibidem & & templo de amor, alcázar de nobleza: & [99] \\
\hline Sol.f. $163[171 \mathrm{r}]$ & 85 & díganlo cuantos tiempos ha que nada & [Sol. II, v. 193] \\
\hline Sol.f. $177[176 \mathrm{v}]$ & & en que la arquitectura & [Sol. II, 669] \\
\hline Ibidem & & para su hermosura, & [Sol. II, v. 668] \\
\hline Sol.f. $177[176 \mathrm{v}]$ & & jaspes calzada, pórfidos vestida. ${ }^{44}$ & [Sol. II, 671] \\
\hline Can.f. $4 \mathrm{r}$ & & Levanta aquel León fiero & [72] \\
\hline Ibidem & 90 & del tribu ${ }^{45}$ de Judá, que honró el madero, ${ }^{46}$ & [72] \\
\hline Can.f. 44 & & treguas hechas süaves & [Sol. I, f. 159r, v. 341] \\
\hline Ibidem & & los fuertes hombros con las cargas graves, & [Sol. I, v. 340] \\
\hline Can. f. $44 \mathrm{r}$ & & que del arco encorvado & [25] \\
\hline D. f. $163[154 \mathrm{v}]$ & & al duro roble, al pino levantado, & {$[D .$, v. 17] } \\
\hline Sol.f. $163 \mathrm{r}$ & 95 & el sagrado laurel, del hierro agudo & [Sol. I, 690] \\
\hline Son. 17 [5r] & & el roto seno de sus minas roto, ${ }^{47}$ & {$[253$, v. 7$]$} \\
\hline Sol.f. $163 \mathrm{r}$ & & deja de su esplendor, deja desnudo, & [Sol. I, v. 691] \\
\hline Sol.f. $155 \mathrm{r}$ & & no lejos de un escollo coronado, & {$[$ Sol. I, v. 24] } \\
\hline Can.f. 40r & & a las purpúreas cruces de sus señas & {$[223$, v. 89$]$} \\
\hline Ibidem & 100 & nuevos calvarios sus antiguas peñas: & {$[223$, v. 90$]$} \\
\hline Sol.f. $149 \mathrm{v}$ & & que sobre el ferro está en aquel incierto & [Sol. I, v. 60] \\
\hline
\end{tabular}

\footnotetext{
${ }^{43}$ Recordemos que, según se aclara al inicio del certamen, el templo había empezado a construirse en tiempos de Cortés, por eso es "cano", por "su edad majestuosa", por eso también se habla de un "muro" descubierto (lo que había antes de que se concluyera la edificación).

${ }^{44}$ vv. 85-88: me parece que para es verbo, con dos posibles acepciones (Dicc. Aut.): terminar algo o adornar. El sentido es que hace mucho la arquitectura, "jaspes calzada, pórfidos vestida", no se veía tan lucida como ahora con el nuevo templo.

${ }^{45}$ Véase supra, nota 17.

${ }^{46}$ El "León fiero" de la tribu de Judá que "honró el madero" es, obviamente, Cristo. En los versos siguientes (91-100), resulta difícil seguir la lógica centonaria. No me queda claro si el "León fiero" es el sujeto de "levanta" o si se trata de un sujeto tácito, que sería el templo, que levanta este templo para Cristo. Mucha madera parece haberse empleado en su construcción: "duro roble", "pino levantado", "sagrado laurel" ("sagrado" porque es el árbol de Apolo), cortados por el "hierro agudo" (el hacha); quedan "desnudos de su esplendor", es decir, como en el original gongorino, despojados de su follaje, los puros troncos.

47 "Y el culto seno de sus minas roto" (253, v. 7).
} 


\begin{tabular}{|c|c|c|}
\hline Ibidem & & golfo de sombras anunciando el puerto, ${ }^{48}$ \\
\hline Sol.f. $161 \mathrm{v}$ & & consagrándole palios a su esposa, \\
\hline Ibidem & & que a mucha fresca rosa \\
\hline Sol.f. 164r & 105 & inmortal arador fue de su pena; \\
\hline Ibidem & & y en la sombra no más de la azucena, \\
\hline Son.f. $15[11 \mathrm{v}]$ & & sembrando su contento o su cuidado ${ }^{49}$ \\
\hline Son.f. $12[11 \mathrm{v}]$ & & por las puertas salía del oriente: \\
\hline Ibidem $[11 \mathrm{v}]$ & & ella de flores la encendida frente, \\
\hline Son.f. $12[11 \mathrm{v}]$ & 110 & él de encendidos rayos coronado, ${ }^{50}$ \\
\hline Pol.f. 151r & & Argos es siempre atento a su semblante, \\
\hline Ibidem & & cíñalo bronce o múrelo diamante, \\
\hline Pan.f. $186 \mathrm{v}$ & & señas dando festivas del contento, \\
\hline Ibidem & & al primero previene Sacramento \\
\hline Pol.f. 150r & 115 & dulcísimo panal, a cuya cera \\
\hline Ibidem & & su néctar vinculó la primavera. \\
\hline Sol.f. $160 \mathrm{v}$ & & Ésta, pues, nave ahora, \\
\hline Ibidem & & tapete del Aurora, \\
\hline Son. $f .7[13 r]$ & & tus himnos canta, tus virtudes reza; \\
\hline Pan.f. $183 \mathrm{v}$ & 120 & el virrey confirmando su gobierno, \\
\hline Ibidem & & ósculo de justicia y paz alterno \\
\hline Sol.f. 161r & & (de nuestros labradores, \\
\hline Sol.f. $158 \mathrm{r}$ & & si Aurora no con rayos, Sol con flores), \\
\hline Pan.f. 183r & & le jura muchas veces a sus plantas \\
\hline Ibidem & 125 & los verdes rayos de aquel árbol solo \\
\hline Can.f. 44 [183v] & & que los abrazos mereció de Apolo..$^{51}$ \\
\hline Sol.f. 176r & & El tiempo vuela: goza, pues, ahora \\
\hline
\end{tabular}

[Sol. I, v. 61]

[Sol. I, v. 568]

[Sol. I, v. 569]

[Sol. I, v. 742]

[Sol. I, v. 743]

[14]

[Polifemo, v. 292]

[Polifemo, v. 294]

[Panegírico, v. 457]

[Panegírico, v. 459]

[Polifemo, v. 207]

[Polifemo, v. 208]

[Sol. I, v. 477]

[Sol. I, 476]

[Panegírico, v. 183]

[Panegírico, v. 184]

[Sol. I, v. 527]

[Sol. I, v. 250]

[Panegírico, v. 183]

[Panegírico, v. 184]

[Panegírico, v. 192]

[Sol. II, v. 601]

${ }^{48}$ Me parece que los versos 101-102 sólo pueden entenderse en relación con el modelo gongorino: como la fogata de los cabreros le anunció puerto al peregrino náufrago, así el templo, donde Hijo y Madre son venerados, es puerto y consuelo, lugar donde se consagran flores a la Virgen ("palios a la esposa", "fresca rosa"), aunque se me escapa la relación con el verso "inmortal arador fue de su pena".

49 "sembraban su contento o su cuidado" (14, v. 5).

50 "Ella" y "él" se refieran a la Virgen y a Cristo (recordemos la doble advocación del templo): ella es como una Aurora con la frente encendida de flores, que anuncia al Sol, coronado "de rayos encendidos" que es Cristo (lo confirman los vv. 122-123, con la efectiva hipálage gongorina: Madre e Hijo están tan imbricados, que la Virgen parece una aurora con rayos - los del Sol/Cristo - y Cristo un Sol con flores - las de la Aurora/María). Cristo es como un Argos (el perro de cien ojos que cuando duerme cierra cincuenta, por lo que siempre está vigilante), continuamente pendiente de su Madre: la exentó del pecado original, es decir, la "previno" del "primero sacramento", esto es, del bautizo (que limpia el pecado original).

${ }^{51} \mathrm{El}$ árbol que mereció, sólo él, los abrazos de Apolo es el laurel. Apolo estaba enamorado de Dafne; ella, para evitar que el dios la tomara, pidió ayuda a los dioses y se transformó en laurel, forma en la que Apolo logró abrazarla. 


$\begin{array}{ll}\text { Ibidem } & \text { los lilios de tu aurora; } \\ \text { Can.f. } 43 \mathrm{r} & \text { goza lo que te ofrece } \\ \text { Son.f. } 4[\mathrm{gv}] & 130 \begin{array}{l}\text { del gran pastor de pueblos que enriquece. }{ }^{52} \\ \text { Ibidem }[\text { f. } 4 \mathrm{v}]\end{array} \\ & \text { Ampáreme tu sombra, peregrino, } \\ & \text { y votaré a tu templo mi camino. }{ }^{53}\end{array}$

\begin{tabular}{|c|c|c|}
\hline $\begin{array}{l}\text { D.f. } 154 \mathrm{r} \\
\text { Ibidem }\end{array}$ & & $\begin{array}{l}\text { Cuantos me dictó versos dulce musa, } \\
\text { en soledad confusa, }\end{array}$ \\
\hline Pol.f. $147 \mathrm{v}$ & & escucha al son de la zampoña mía, \\
\hline Son.f. 10r & & ilustre y hermosísima María, \\
\hline Son. $f .16 \mathrm{r}$ & 5 & bellos efectos, pues la causa es bella. ${ }^{54}$ \\
\hline Pol.f. $147 \mathrm{v}$ & & Alterna con las Musas hoy el gusto, \\
\hline Oct.f. $146 \mathrm{r}$ & & por que Talía mejor los triunfos cante* \\
\hline Ibidem & & en cítara sonante;* \\
\hline Pol.f. $147 \mathrm{v}$ & & que si la mía puede ofrecer tanto, \\
\hline Son.f. 15 [16r] & 10 & siendo tuya la voz y el canto de ella ${ }^{55}$ \\
\hline Can.f. $43 \mathrm{r}$ & & dulzuras acrecientan a dulzuras. \\
\hline Ibidem & & El rubio dios recuerda ${ }^{56}$ \\
\hline Ibidem & & y, pulsando una dulce y otra cuerda, \\
\hline Ibidem & & de suavidad ahora el prado baña, \\
\hline Ibidem & 15 & y con arte no poca, \\
\hline Ibidem & & las flores trasladando de su boca \\
\hline Ibidem & & (perpetuamente vivas), \\
\hline Ibidem & & a la sacra vigüela \\
\hline Ibidem & & alimento las hace de las Musas, \\
\hline Ibidem & 20 & el docto enjambre que sin alas vuela,$^{57}$ \\
\hline
\end{tabular}

[Sol. II, v. 602] $\mathbf{3}$
$\begin{gathered}\text { Primer lugar } \\ \text { de don Alonso Ramírez de Vargas }\end{gathered}$
Cuantos me dictó versos dulce musa,
en soledad confusa,
escucha al son de la zampoña mía,
ilustre y hermosísima María,
bellos efectos, pues la causa es bella. ${ }^{54}$
Alterna con las Musas hoy el gusto,

$\mathbf{3}$
$\begin{gathered}\text { Primer lugar } \\ \text { de don Alonso Ramírez de Vargas }\end{gathered}$
Cuantos me dictó versos dulce musa,
en soledad confusa,
escucha al son de la zampoña mía,
ilustre y hermosísima María,
bellos efectos, pues la causa es bella. ${ }^{54}$
Alterna con las Musas hoy el gusto,

$\mathbf{3}$
$\begin{gathered}\text { Primer lugar } \\ \text { de don Alonso Ramírez de Vargas }\end{gathered}$
Cuantos me dictó versos dulce musa,
en soledad confusa,
escucha al son de la zampoña mía,
ilustre y hermosísima María,
bellos efectos, pues la causa es bella. ${ }^{54}$
Alterna con las Musas hoy el gusto,

[Polifemo, v. 22]

${ }^{52} \mathrm{El}$ "gran pastor de pueblos que enriquece" es el virrey que permitió la conclusión del templo.

${ }^{53}$ vv. 131-132: 'Que tu sombra [la del templo] me ampare a mí, peregrino, y cual peregrino, te entregaré mi camino como exvoto'.

54 'Ilustre y hermosísima María [la Virgen], escucha al son de mi zampoña, en soledad confusa, los versos que me dictó la dulce musa, versos que son efectos bellos pues tú, causa bella, los inspiras'.

${ }^{55}$ La voz (el contenido del canto) de la cítara del poeta proviene de María y el canto (la música, la forma) de Talía.

56 "El rubio dios" es Apolo, el sol; "recuerda": despierta; esto es, amanece.

${ }^{57}$ Muy ingeniosa la trabazón de los vv. 19-20: las Musas, cual abejas, beben de las flores que abre el sol (esto es, de la inspiración de Apolo) para producir no miel, como las abejas, sino 


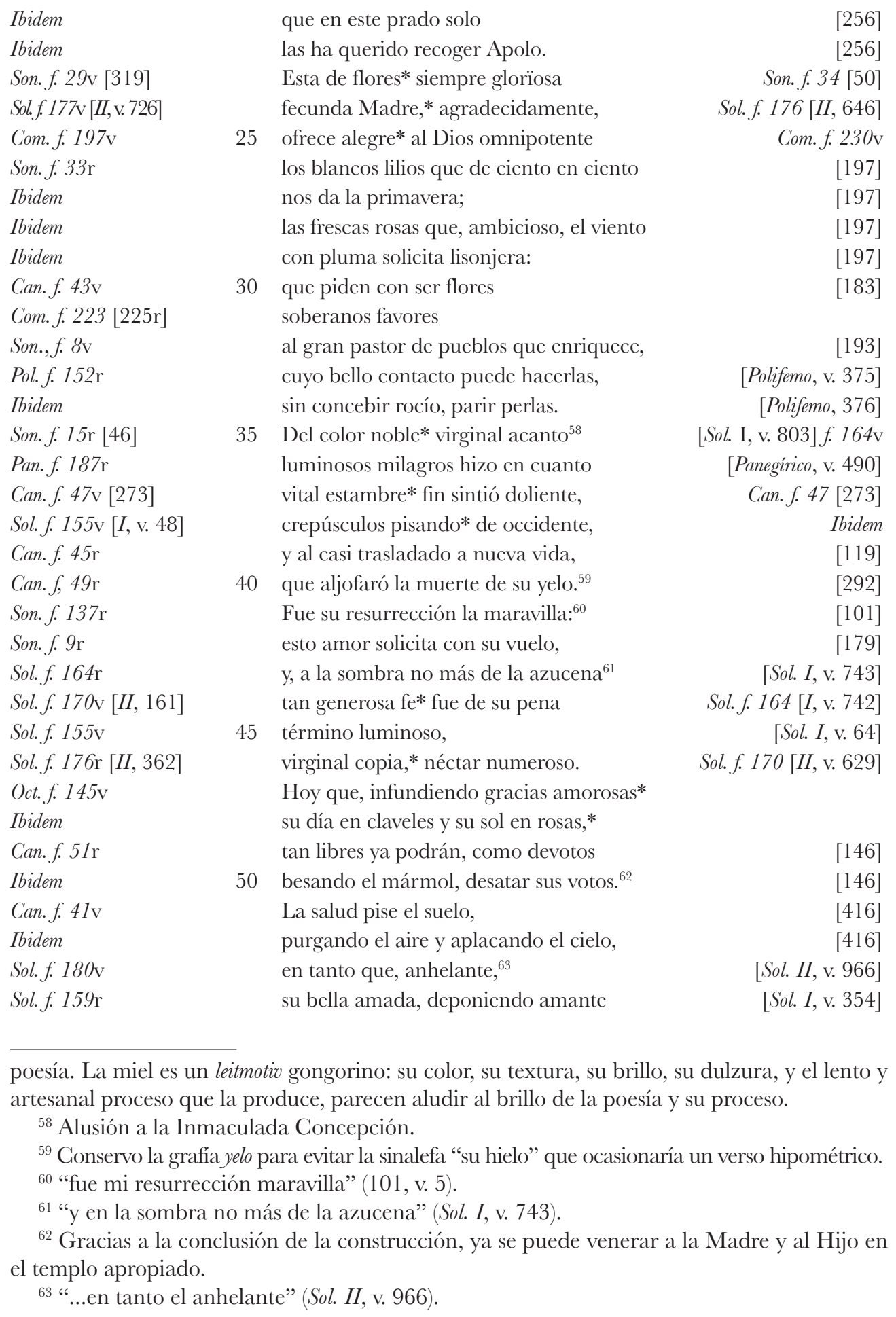




\begin{tabular}{|c|c|c|}
\hline Ibidem & 55 & de las vestidas rosas su cuidado, \\
\hline Son.f. $5 \mathrm{r}$ & & con rayos dulces mil de sol templado ${ }^{64}$ \\
\hline Pol.f. 150 [166r] & & quiere que a él rinda en desiguales días ${ }^{65}$ \\
\hline Pol.f. $151 \mathrm{v}$ & & el lilio sus matices, si bien era \\
\hline Sol.f. $172 \mathrm{v}$ & & en breve espacio mucha primavera \\
\hline Pol.f. $150 \mathrm{v}$ & 60 & mil veces ofrecida, \\
\hline Ibidem & & si bien al dueño debe, agradecida, \\
\hline Ibidem & & su deidad culta* en las prisiones bellas ${ }^{66}$ \\
\hline Ibidem & & de la esfera mayor de sus centellas; \\
\hline Son. f. $33 \mathrm{r}$ & & que fuego él expirando, \\
\hline Can.f. $53 \mathrm{r}$ & 65 & el un pecho da al celo, el otro al culto, \\
\hline Can.f. $48 \mathrm{v}$ & & un generoso anima y otro bulto \\
\hline Son. f. $38 \mathrm{v}$ & & de cristiano valor y de fe ardiente \\
\hline Son. $f .4 \mathrm{v}$ & & este ya de justicia sol luciente, \\
\hline Can.f. $52 \mathrm{v}$ & & su forma de la más sublime llama, \\
\hline Son. f. $38 \mathrm{v}$ & 70 & alas vistiendo no de mortal fama, \\
\hline Son.f. 22v [307] & & generosa piedad* fabrica templo. \\
\hline Oct.f. 171 & & Pues, ¡ay Alcides* de tan alto ejemplo!,* \\
\hline Son.f. $4 \mathrm{r}$ & & clarísimo marqués, dos veces claro: ${ }^{67}$ \\
\hline Pan.f. 181v & & éste, a quien guardará mármoles Paro ${ }^{68}$ \\
\hline Pan.f. $187 \mathrm{v}$ & 75 & mayor será trofeo la memoria, \\
\hline Ibidem & & que el adelantamiento a su victoria, \\
\hline Oct.f. $144 \mathrm{r}$ & & que eterno se recibe* \\
\hline Ibidem & & el que en las lenguas de los hombres vive.* \\
\hline Son.f. $13 \mathrm{r}$ & & De pura honestidad templo sagrado, \\
\hline Son. f. $22 \mathrm{v}$ & 80 & majestuosamente levantado, \\
\hline
\end{tabular}

[Sol. I, v. 355]

[Sol. I, v. 906]

[Polifemo, v. 314]

[Sol. II, v. 339]

[Polifemo, 229]

[Polifemo, v. 230]

Can.f. $42 \mathrm{v}$ [184]

[184]

Ler.f. 187 [v. 528]

Oct.f. 171

[162]

[Panegírico, v. 29]

[Panegírico, v. 543]

[Panegírico, v. 544]

${ }^{64}$ Otra vez la idea de la Virgen como Aurora (llena de flores) que anuncia al Sol/Cristo.

65 "fecundo os rinda en desiguales días" (Sol. I, v. 906).

${ }^{66}$ La "deidad culta" (a la que se le rinde culto) es la Virgen María, quien debe a "su dueño" (el promotor de la obra, es decir, el virrey) tener un lugar consagrado a ella. En los vv. 65-67, se alude al pecho valeroso, a la fe ardiente y al celo del marqués.

${ }^{67}$ Alcides es Hércules, nieto de Alceo. La obra del virrey (la conclusión del templo) se compara con los trabajos de Hércules, por eso le llama "Alcides".

${ }^{68}$ Decidí corregir el verso de acuerdo con el modelo, pues de lo contrario, no tiene sentido. En el centón se cita así: "éste, a quien guardarán mármoles paro", entendiendo que el sujeto es "mármoles" y el objeto directo "éste" (el templo); "paro" es el gentilicio de Paros, lugar de mármol por excelencia; para calificar a "mármoles", tendría que estar en plural; y no creo que la solución fuera: "éste, a quien guardarán mármoles, paro", es decir, "este paro (templo todo de mármol) será guardado (eternizado) por mármoles'. Además, en el español de esa época se conserva el uso latino de los gentilicios con mayúsculas. Quizá el error sea del formador que, simplemente, no entendió el verso. Supongo que Ramírez de Vargas sabía qué estaba diciendo. 


\section{Centones gongorinos en Nueva España}

\begin{tabular}{|c|c|c|c|}
\hline \multirow{2}{*}{\multicolumn{2}{|c|}{$\begin{array}{l}\text { Pol.f. } 148 \mathrm{v} \\
\text { Pol.f. } 150 \mathrm{v}\end{array}$}} & de las oscuras aguas del Leteo ${ }^{69}$ & {$[$ Polifemo, v. 58] } \\
\hline & & ostentación gloriosa, alto trofeo & [Polifemo, v. 238] \\
\hline Com. f. 205r & & en la materia y en el artificio, & \\
\hline Son.f. $8 \mathrm{r}$ & & de la imperial ciudad patrio edificio. & {$[67]$} \\
\hline Ibidem [f. 8v] & 85 & Aquí la primavera ofrece flores & [193] \\
\hline Son.f. $12 \mathrm{r}$ & & que el cielo pinta de cien mil colores ${ }^{70}$ & {$[51]$} \\
\hline Son.f. $23 \mathrm{v}$ & & flores que ilustra otra mejor Aurora, & [219] \\
\hline Can.f. $49 \mathrm{r}$ & & un Alba que crepúsculos ignora; ${ }^{71}$ & [292] \\
\hline Son. f. 34v & & que privilegia el cielo & {$[50]$} \\
\hline Son.f. $12 \mathrm{v}$ & 90 & con diferencia tal, con gracia tanta, ${ }^{72}$ & [40] \\
\hline Sol.f. 176v [II, v. 626] & & el peregrino* espíritu levanta & Son. f. $12 \mathrm{v}[40]$ \\
\hline Son. f. 13r [16] & & tanta belleza* del purpúreo seno. & Son.f. 10r [41] \\
\hline Son.f. $23 \mathrm{r}$ & & Esta en forma elegante & [269] \\
\hline Oct.f. 150r [v. 185] & & salamandra del Sol* ninguno siente & Son.f. 1v [39] \\
\hline Sol.f. 169v [II, v. 87] & 95 & contagio original* un solo instante, ${ }^{73}$ & Com.f. $205 \mathrm{v}$ \\
\hline Can.f. $48 \mathrm{v}$ & & aquí donde coloca & [308] \\
\hline Son. f. $3 \mathrm{v}$ & & tributo humilde, fino ofrecimiento, & [172] \\
\hline Ler.f. $84 \mathrm{r}$ & & luz nueva al firmamento & [Panegírico, v. 230] \\
\hline Ibidem & & en nueva imagen, dulce compañía, & [Panegírico, v. 231] \\
\hline Son. f. $31 \mathrm{r}$ & 100 & pues que lo quiso así la suerte mía, ${ }^{74}$ & [393] \\
\hline Can. f. $51 \mathrm{r}$ & & reclinatorio es de su gran dueño, & [416] \\
\hline Ibidem & & timón del vasto ponderoso leño, & {$[416]$} \\
\hline Sol.f. $155 \mathrm{r}$ & & piadoso miembro roto, & [Sol. I, v. 17] \\
\hline Can.f. $45 \mathrm{v}$ & & que escogió entre los árboles del soto, & {$[114]$} \\
\hline Ibidem & 105 & y tálamo luego: & {$[114]$} \\
\hline Ibidem & & árbol que tanto fue perdone el fuego $;^{75}$ & [114] \\
\hline Sol.f. $158 \mathrm{v}$ & & trofeo ya su número es a un hombro, & [Sol. I, v. 307] \\
\hline Ibidem & & si carga no y asombro. & [Sol. I, v. 308] \\
\hline
\end{tabular}

\footnotetext{
${ }^{69}$ El Leteo es el río del olvido. Este majestuoso templo quedará para siempre, nunca será olvidado.

70 "que el suelo pinta de cien mil colores" (núm. 51, v. 11).

${ }^{71}$ Esa "mejor Aurora" que "ignora crepúsculos" (manchones oscuros, esto es, el pecado original) es la Virgen María. El verso gongorino dice: "de una alba que crepúsculos ignora" (núm. 292, v. 6).

${ }^{72}$ Hermosa e ingeniosa la trabazón de los vv. 89-90.

${ }^{73}$ La "Salamandra del Sol” es María. Según el Dicc. Aut., por su humedad resiste el calor y el fuego, no la quema. La Virgen se compara con la Salamandra porque tampoco siente el "ardor" del pecado, y puede estar junto al Sol que es Cristo (pues el templo les rinde veneración a los dos).

74 "Pues lo ha querido así la suerte mía" (núm. 393, v. 2).

${ }^{75}$ Los vv. 101-106 parecen aludir a los labrados de madera: los "piadosos miembros rotos" de algún árbol, que decoran y sirven de sostén. El piadoso árbol de donde se obtuvo esa madera no será víctima del fuego.
} 
Can.f. $45 \mathrm{r}$

Sol.f. 159r [I, v. 337$]$

Son. f. 36v [35]

Sol.f. 160r

Can.f. 45r [119]

Pol.f. 150v [v. 246]

Sol.f. 155r [I, v. 25]

Can.f. 46v

Ibidem

Com.f. 231r

Son.f. 3r [172]

Sol.f. $155 \mathrm{r}$

Son. f. $12 \mathrm{v}$

Ibidem

Sol.f. $159 \mathrm{v}$

Son.f. 35r [390]

Oct.f. $144 \mathrm{v}$

Pol.f. 150v [v. 227]

Son.f. 31r

Sol.f. 164v

Can.f. 53r

Son.f. 13r [16]

Son. f. $3 \mathrm{r}$

Son.f. $9 \mathrm{r}$

Oct.f. $145 \mathrm{v}$

Can.f. 43v

Oct.f. $145 \mathrm{v}$

Son.f. 22v

Pol.f. 151r

Son.f. 10r

Can.f. 51v [410]

Son.f. 2r [179]
Y aunada a su cuello ${ }^{76}$

[119]

110 fragosa cuerda* pendiente, cuando

goza el color* vestir de vulto ${ }^{77}$ bello

Can.f. 49r [308]

Son.f. 13v [43]

[Sol. 11, v. 36]

de cáñamo fiando

a los lazos de amor* dichosos nudos

con más cuidado* viendo su belleza,

115 de secos juncos* ciñe su cabeza.

Can.f. 45r [119]

Son.f. 15r [46]

Ibidem

[274]

Aquí, pues, al cuidado

el mísero gemido

que dio un enfermo* cual con voz doliente

120 halló hospitalidad, donde halló nido. ${ }^{78}$

Son.f. 11v [14]

[Sol. I, v. 27]

[99]

[99]

templo de amor, alcázar de nobleza.

En esta, pues, fiándose atractiva

flamante llama, ${ }^{79 *}$ así pagó, obediente*

[Sol. I, v. 393]

Oct.f. $144 \mathrm{v}$

125 su Madre el celo ardiente,*

agradecida* cuanto generosa,

a la satisfacción se disponía,

Sol.f. $177 \mathrm{v}[I I, \mathrm{v} .737]$

Virgen tan bella, ¿qué hacer podía? ${ }^{80}$

[Sol. I, v. 783]

[363]

130 ¡Oh claro honor de* la florida falda!

Casta Madre, hija bella,

Can.f. 43v [183]

[174]

recibe los que en rayos, si no flores, ${ }^{*}$

tejidos en guirnalda

eternos resplandores*

con majestad vincula con decoro.

De sitio mejorada, atenta mira

[Polifemo, v. 273]

si expira suavidad, si gloria expira.

Bellísima, pues, tu* magnificencia,

140 sacro pastor* de rayos coronado: ${ }^{81}$
Can.f. 53r [363]

Son.f. 2r [179]

76 "y anudada a su cuello" (núm. 119, v. 34).

77 "vulto": latinismo por "rostro".

${ }^{78}$ Otra vez la alusión al amparo que significa el templo a la Inmaculada, que es, como dice el verso siguiente, el "Fénix (por ser única) de mayor belleza".

79 "Oro no rayo así flamante grana" (núm. 390, v. 1).

${ }^{80}$ En el verso de Góngora no hay interrogación; se trata de una virgen (doncella) tan bella que podría hacer tórrida Noruega. El juego en la recreación centonaria parece ser: ¿qué otra cosa podía hacer la Virgen, después de haber sido privilegiada por Dios, que estar agradecida y responder con "celo ardiente"?

${ }^{81}$ La "magnificencia bellísima" es la del marqués, que es aquí, nuevamente, el "sacro pastor" (que conduce/gobierna a su grey). 
Can.f. $42 \mathrm{v}$

Son.f. 23v [219]

Sol.f. $176 \mathrm{r}$

Can.f. $43 \mathrm{r}$

Ibidem

Can.f. 49

Can.f. $43 \mathrm{v}$

Ibidem
Por este culto, bien nacido prado, ya en nuevos campos, ${ }^{*}$ goza, pues, ahora los lilios de tu Aurora; goza sus bellas plantas,

145 que maravillas tantas (bien que milagros despreciando egipcios) ${ }^{82}$ admiraciones son y desenojos, néctar del gusto y gloria de los ojos.
Sol.f. 176r [II, v. 601]

[Sol. II, v. 602]

\section{4}

Primer lugar

Bachiller don Félix López Muñiz

\begin{tabular}{|c|c|c|}
\hline \multicolumn{3}{|l|}{ Pol.f. } \\
\hline Pan.f. 181r & & tu dictamen, Euterpe, soberano, \\
\hline Son.f. $13 \mathrm{v}[17]$ & & para que de esta* exaltación instada \\
\hline Son. f. $12 \mathrm{v}$ & & y generosamente edificada, \\
\hline Son. $f .2 \mathrm{r}$ & 5 & cante Apolo de rayos coronado, \\
\hline Ibidem & & no humilde musa de laurel ceñida. \\
\hline Son. f. $1 \mathrm{v}$ & & Apolo en vez de pájaro nevado, \\
\hline Terc.f. $55 \mathrm{v}$ & & alto asunto, materia esclarecida, \\
\hline Sol.f. $160 \mathrm{v}$ & & a la inmortal memoria, \\
\hline Son.f. 13r [16] & 10 & con regalado son* al blando viento \\
\hline D. . $154 \mathrm{v}$ & & su canoro dará dulce instrumento. \\
\hline Sol.f. $170 \mathrm{v}$ & & Selle sí más no oprima \\
\hline Son. f. $22 \mathrm{v}$ & & esta, pues, siempre fábrica, esta prima \\
\hline Son. $f .2 \mathrm{v}$ & & sacra erección de príncipe glorioso, \\
\hline Son. f. 33r & 15 & esplendor generoso \\
\hline Sol.f. $164 \mathrm{v}$ & & a su ardiente deseo, \\
\hline Pol.f. $150 \mathrm{v}$ & & ostentación gloriosa, alto trofeo. \\
\hline Sol.f. 156r & & ¡Oh bienaventurado \\
\hline Ibidem & & albergue a cualquier hora, ${ }^{83}$ \\
\hline Son. f. 2v [194] & 20 & del reino escudo, ${ }^{*}$ gloria del estado \\
\hline Sol.f. $156 \mathrm{r}$ & & templo de Pales, alqueria ${ }^{84}$ de Flora, \\
\hline Ibidem & & no moderno artificio, \\
\hline Son.f. $8 \mathrm{r}$ & & de la imperial ciudad patrio edificio \\
\hline
\end{tabular}

Pan.f. 181r [v. 4]

[Panegírico, v. 2]

Can.f. 51r [416]

[Sol. I, v. 479]

Son. f. $14 \mathrm{v}$ [44]

[v. 36]

[Sol. II, v. 169]

[Sol. I, v. 778]

[Polifemo, v. 238]

[Sol. I, v. 94]

[Sol. I, v. 95]

Son.f. 4r [160]

[Sol. I, v. 96]

[Sol. I, v. 97]

\footnotetext{
${ }^{82}$ Supongo que los "milagros egipcios" son las pirámides, cuya arquitectura desmerece ante la del nuevo templo.

${ }^{83}$ Vuelve la idea del amparo al referirse al templo como "bienaventurado albergue".

${ }^{84}$ alqueria: como en Góngora, hay que conservar la sinéresis, de lo contrario, el verso resultaría hipermétrico.
} 


Sol.f. $176 \mathrm{v}$
Ibidem
Ibidem
Son.f. $22 \mathrm{r}$
Sol.f. $176 \mathrm{v}$
Can.f. $43 \mathrm{v}$ [25]
Sol.f. $165 \mathrm{r}$
Ibidem
Sol.f. $176 \mathrm{v}$
Sol.f. $162 \mathrm{r}$
Sol.f. $168 \mathrm{v}$
Son.f. $1 \mathrm{r}[266]$
Sol.f. $158 \mathrm{r}[I I, \mathrm{v} .249]$
Terc.f. $57 \mathrm{r}$ [202]
Son.f. $3 \mathrm{r}$
Son.f. $23 \mathrm{r}$
Son.f. $10 \mathrm{r}$
Son.f. $29 \mathrm{v}[354]$
Sol.f. 164v
Ibidem
Pol.f. $152 \mathrm{v}$
Sol.f. $164 \mathrm{v}$
Sol.f. $165 \mathrm{v}[I, \mathrm{v} .862]$
Ler.f. $186 \mathrm{v}$
Son.f. 4r
Sol.f. $165 \mathrm{v}$

en que la arquitectura

25 para su hermosura, ${ }^{85}$

jaspes calzada y pórfidos vestida,

si a más gloriosa Fénix construida,

a la geometría se rebela,

al soberbio Aquilón* sin alas vuela.

30 Verde muro de aquel lugar pequeño,

artífice, tejió la primavera, ${ }^{86}$

concediólo risueño, ${ }^{87}$

calzada abriles y vestida mayos.

No, pues, de otra manera,

35 siempre glorioso, * saludó sus rayos,

o matizado* de lo que produce,

pastor de ovejas:* que entre hierbas luce ${ }^{88}$

soberana beldad, valor divino,

que dio espíritu al leño y vida al lino,

40 entre los lilios mora

de los aromas* que troncó el Aurora. ${ }^{89}$

Aurora de sus ojos soberanos,

Virgen tan bella,* pompa de las flores,

sudando néctar, lambicando olores,

45 claveles del abril, rubíes tempranos,

ofrece ahora* Madre esclarecida,

que ilustró el hemisferio de la vida

claro, no ha luces hoy de lisonjero,

con pecho igual de aquel candor primero. ${ }^{90}$
[Sol. II, v. 670]

[Sol. II, v. 671]

[Sol. II, v. 672]

[Sol. II, v. 269]

Can.f. 43r [256]

[Sol. I, v. 523]

[Sol. I, v. 524]

[Sol. II, v. 645]

[Sol. I, v. 577]

[Sol. II, v. 22]

Sol.f. $177 \mathrm{v}[I I, \mathrm{v} .731]$

Terc.f. 57v [202]

Ibidem [202]

Pol.f. 152r [v. 362]

[Sol. I, v. 782]

Sol.f. 164r [I, v. 759]

[Polifemo, v. 393]

[Sol. I, v. 786]

Ler.f. 185r [v. 433]

[Panegírico, v. 435]

[Sol. I, v. 862]

${ }^{85}$ La arquitectura encontró en este templo el colmo de su hermosura.

${ }^{86}$ Como en Góngora, "artífice" funciona como ablativo absoluto: 'la Primavera tejió, cual artífice/ siendo artífice'.

${ }^{87}$ No es clara la idea (además de que el verso queda suelto). ¿La primavera concedió ese verde muro risueño (por lo agradable, ameno, florido), como locus amoenus, para la construcción del templo? Porque lo que sí resulta lógico es que sea la primavera la "calzada abriles y vestida mayos", meses de flores, primaverales por excelencia.

88 “...que en las hierbas luce" (núm. 202, v. 94).

${ }^{89}$ vv. 34-41: 'No, pues, de otra manera [que como se admira la arquitectura del templo], el pastor de ovejas [supongo que el virrey], siempre glorioso o matizado [adornado] de lo que produce, saludó sus rayos [los rayos de la Aurora/Virgen], pues entre las hierbas luce, la soberana beldad [la Virgen], el valor divino [Cristo], que dio espíritu al leño y vida al lino, y mora entre los aromas de los lirios que tronchó la aurora'.

${ }^{90}$ vv. 42-49: '[Esa beldad que luce entre las yerbas] es la Aurora de sus ojos soberanos [no me queda claro si los ojos son los de Cristo o los del virrey], virgen bella, pompa de las flores, que sale sudando néctar y lambicando olores, Madre esclarecida que ahora ofrece claveles del abril y rubíes tempranos. Esa Madre que ilustró [cultismo por iluminó] el claro [en el sentido de 
Son.f. 10v [24]

Ler. f. $187 \mathrm{r}$

Son.f. 2r [179]

Ler.f. 187r [v. 490]

Can.f. 39v [223]

Ler. f. $187 \mathrm{r}$

Sol.f. $185 \mathrm{r}$

Ibidem

Can.f. 43r [256]

Ler. f. $183 \mathrm{r}$

Sol.f. 158r [I, v. 258]

Can.f. 40r

Sol.f. 161v

Sol.f. $174 \mathrm{r}$

Sol.f. 176v

Sol.f. 155r [I, v. 4]

Pol.f. 152r [v. 375]

Son.f. 37v [322]

Son. f. 9v [441]

Sol.f. $178 \mathrm{v}[I I$, v. 821$]$

Son.f. 10r

Son. f. $12 \mathrm{v}$

Ibidem

Sol.f. 155r [I. V. 5]

Sol.f. $176 \mathrm{r}$

Can.f. $43 \mathrm{r}$

Ibidem

Ibidem

Ibidem

Ibidem

Pol.f. 153r [v. 432]

Son. f. 9r [100]

Son. f. $27 \mathrm{v}[60]$

Son.f. 38r*
50 Mientras por competir* gloriosamente rayos dorando en toda edad luciente, sacro pastor de* nombre esclarecido ${ }^{91}$ luminosos milagros* ha ofrecido, agradecida* Madre imita al hijo,

55 vestida siempre de frondosas plantas, inundación hermosa que la montaña hizo populosa, jardín de Febo,* artífice prolijo (homenaje recíproco) otras tantas

60 rosas traslada,* más que abeja flores, a los dorados luminosos fuegos, que a mucha fresca rosa del virginal decoro coronados traslada de favores

65 todos los rayos* Dios del alto coro, cuyo bello contacto* ciento en ciento las hojas inflamó* del ardimiento, las rosas que al Aurora de esclarecido* estado más sereno

70 se le cayeron del purpúreo seno. Templo de amor, alcázar de nobleza, nido del Fénix de mayor belleza, honor del cielo, ${ }^{*}$ goza, pues, ahora ${ }^{92}$ los lilios de tu Aurora,

75 sacras plantas perpetuamente vivas, que maravillas tantas, émulas no de palmas ni de olivas, admiraciones son y desenojos, néctar del gusto y gloria de los ojos.

80 Do halló reparo, * rico albergue luego, descaminado, enfermo, ${ }^{*}$ sordo y ciego, porque a tanta salud se ha restituido ${ }^{93}$ tu hermosura,* la Aurora, el Sol dorado
Son.f. 2r [251]

[Panegírico, v. 498]

Son.f. 30r [312]

Sonf. 5v [233]

Pol.f. 153r [v. 462]

[Panegírico, v. 490]

[Sol. I, v. 263]

[Sol. I, v. 264]

Pol.f. 153r [v. 458]

[Panegíicico, v. 182]

Pol.f. 152v [v. 395]

[Sol. I, v. 569]

[Sol. II, v. 462]

[Sol. II, v. 649]

Son.f. 27v [60]

Son. f. 33r [97]

Son.f. $14 \mathrm{v}[44]$

Son. f. 16r [23]

Sol.f. 176r [II, v. 601]

[Sol. II, v. 602]

Son.f. 11v [14]

Ibidem [100]

Son.f. 11v [14]

'verdadero'] y no lisonjero [mentiroso] hemisferio, con el candor primero [exenta del pecado original]'.

${ }^{91}$ Considero que este "sacro pastor de nombre esclarecido" alude al virrey que compite en gracias y favores con la Virgen por haber permitido la conclusión del templo. De aquí hasta el v. 70, parece que se habla de la reciprocidad de la Virgen ante tal muestra de devoción y amor.

${ }^{92}$ Como en los otros dos centones, en esta parte final se apostrofa al templo: es éste "templo de amor, alcázar de nobleza, nido del Fénix [la Virgen]", etc.; en donde hallaron "reparo" (lugar, amparo) Madre e Hijo ("ella de flores la rosada frente, él de encendidos rayos coronado"). 93 "Porque a tanta salus se ha restituido" (núm. 60, v. 9). 
Son.f. 13r [13]

Son.f. $11 \mathrm{v}$

Ibidem

Sol.f. 164r [I, v. 737]

Son.f. $31 \mathrm{v}^{*}$

Terc.f. 57r [202] coronan de belleza* en nuevo oriente:

85 ella, de flores la rosada frente,

él de encendidos rayos coronado.

Este, pues, Sol* con rayos y con flores, ciñendo el tronco* con rayada espina, pacífico se esconde* o se reclina.
Son.f. 22r [238]

Sol.f. 185r [I, v. 250] Sol.f. 173r [II, 365]

Terc.f. 156r [202]

\section{5}

Primer lugar

Francisco de Ayerra y Santa María

Poniendo ley al mar* robusto pino, velero bosque de árboles, ${ }^{*}$ al viento que lo trata imperioso,* alado roble en campo azul* del líquido elemento

5 desata montes* de inquïeto lino, de escollos mil* no hay cabo que no doble.

El príncipe troyano* el hurto noble, ${ }^{94}$ de lo que ilustre luego en el farol de Tetis* hurtó al fuego,

10 parte a llevar* en tan inciertos mares: deidad que en isla* Delfos algún día ínclito es rayo,* métrica armonía, término fue* deste prudente $\mathrm{Numa}^{95}$ que a sus aras llegó,* pureza suma,

15 orbe ya hermoso de sus* patrios lares, esfera celestial* donde devoto peregrino gentil* cumplió su voto. Propicio albor,* oráculo prudente,

20 el garzón frigio ${ }^{96 *}$ (¿cuándo ya en el puerto?97 con naval pompa* de victoria armado, este jardín* no pisa con pie incierto) oye piadoso, ${ }^{*}$ admira reverente:
Son.f. 15 [v 22]

Son.f. $6[1 \mathrm{lv} 32]$

Sol.f. 159 [r I, v. 394]

Sol.f. 174 [r II, v. 472]

Son.f. 3 [r 163]

Sol.f. 159 [r I, 395]

Son.f. 32 [v 338]

Son.f. 34 [r 441$]$ Sol.f. 161 [r, I, v. 499] Can.f. 43 [v, 256, v. 51]

Ibidem [v. 50]

Terc.f. $55[$ r, 272, v. 7$]$ Oct.f. 55 [r 399, v. 11]

Oct.f. $145[\mathrm{v}]$

Oct.f. 143

Ibidem [v]

Son.f. 28 [r 331$]$

Can.f. 39 [v 223]

Can.f. $41[\mathrm{v} 146]$

Com.f. 189 [v, v. 10]

Can.f. 39 [r 223]

${ }^{94}$ El príncipe troyano es Eneas, aquí representación del virrey, y el "hurto noble" debe referirse a la estatua de la diosa Vesta, que, huyendo del incendio y destrucción de Troya, Eneas se llevo junto con su padre Anquises. Aquí, esa diosa Vesta es alegoría de María.

${ }^{95}$ Numa: segundo rey de Roma, autor de varias reformas culturales y religiosas. Se lo relaciona con el virrey por la protección y devoción del marqués de la Laguna hacia la doctrina de la Inmaculada Concepción.

${ }^{96} \mathrm{El}$ "garzón frigio": el joven troyano, o sea, Eneas.

97 ‘CCómo, en qué momento llegó ya al puerto?’, o algo así. 


\section{Centones gongorinos en Nueva España}

Can.f. 42 [r 165]

Son.f. 4 [r 169]

Can.f. 41 [v 146]

Son.f. 4 [r 169]

Loaf. $144[\mathrm{v}]$

Son.f. 2 [v 194]

Sol.f. 159 [v, I, v. 304]

Son.f. 5 [r 253]

Can.f. 39 [v 223]

Son.f. 4 [r 169]

Pan.f. 185 [r, v. 318$]$

Can.f. 41 [v 146]

Son.f. 5 [r 306]

Pan.f. 182 [r, v. 90]

Ibidem [v, v. 109]

Son.f. 3 [r 163]

Loaf. 145 [v]

Rom.f. 96 [v 150]

Son.f. 9 [r 174]

Son.f. 32 [r 421

Son.f. 1 [v 39]

Can.f. 41 [v 146]

Sol.f. 165 [r, I, v. 815]

Pol.f. 148 [v, v. 78]

Son.f. 12 [r 51]

Son.f. 4 [r 162]

Son.f. 6 [v 220]

Com.f. 204

Loaf. $144[\mathrm{v}]$

Son.f. 2 [r 25]

Oct.f. 146 [r]

Son.f. 2 [1v 311$]$

Loaf. $143[\mathrm{v}]$

Son.f. 1 [v 39]
"Veis — dice el Dios —* el cielo destinado

25 a más os tiene:* oirá el Clarín dorado

(¿deidad tanta se engaña?),

de vuestra fama* sol, cuanto el mar baña

la heroica frente* de laurel ceñida,

la antigua casa* de real corona,

30 del norte* helado a la abrasada zona

con rayos dulces mil* valor fecundo,

duro yugo a los* términos del mundo,

de sucesión real* esclarecida

en púrpura romana* dará flores

35 de monarcas, * de grandes, de señores".

Generoso esplendor,* ;oh tú, de España, ${ }^{98}$

firme columna, ${ }^{*}$ estrella de Medina ${ }^{99}$

de los tres lilios reales ${ }^{100 *}$ copia bella, soberana beldad,* si no divina,

40 de aquella hermosa flor* que te acompaña,

dos lucientes estrellas* la que sella,

delante quien el sol* aun no es estrella,

hará vuestra memoria

del tiempo y del olvido* la victoria!:

45 Madre de perlas ahora* en vez de flores

la admire el mundo,* cuide real fortuna cuna dorada* de sus hijos cuna:

del verde honor* tu casa esclarecida, ${ }^{101}$

clarísimo marqués, ${ }^{*}$ laurel ceñida,

50 zodíaco luciente* de señores

verá desde hoy* con pasos tan seguros

tierra y mares* ceñir, picar coluros.

No es voz de deidad ésta consultada, ${ }^{102}$ que el que idolatra Delos* más ardiente

55 dora el sol* en oráculo profano;

de la Virgen* al templo indeficiente ${ }^{103}$

debéis con gran razón* edad dorada,
Son.f. 4 [r 169]

Ibidem [r 169]

Ibidem [r 169]

Son. f. 2 [r 179]

Pan.f. 182 [v, v. 121]

Can.f. 41 [r 72]

Pan.f. 182 [v, v. 116]

Pol.f. 147 [v, v. 24]

Son.f. 2 [r 179]

Son.f. 2 [r 251]

Son.f. 26 [v 144]

Pan.f. 182 [r, v. 89]

Ibidem [v, v. 112]

Pol.f. 148 [r, v. 47]

Son.f. 4 [r 169]

Can.f. 51 [v 416]

Sol.f. 159 [v, I, v. 390]

Can.f. 48 [v 293]

Son.f. 16 [v 449]

Son.f. 26 [v 171]

Can.f. 41 [v 146]

Son.f. 6 [v 220]

Son.f. 2

Ibidem

Son.f. 33

Loaf. 145

Ibidem

Sol.f. 179 [r, II, v. 880]

Son.f. 2 [r 251]

Loaf. $142[\mathrm{v}]$

Son.f. 10 [v 24]

${ }^{98}$ A partir de aquí el apóstrofe lírico es a la virreina, ya no al virrey.

${ }^{99} \mathrm{El}$ esposo de la virreina, el virrey Tomás de la Cerda, fue el cuarto hijo de Antonio de la Cerda, VII duque de Medinaceli.

${ }^{100}$ La corona española tenía tres puntas, cada una decorada con un lirio.

${ }^{101}$ Regresa el apóstrofe al virrey.

${ }^{102}$ En este verso el poeta hizo trampa, pues cita un endecasílabo completo, en lugar del hemistiquio pedido.

103 "indeficiente": lo que no puede faltar. 
Son. f. 13 [r 16]

Son.f. 3 [v 163]

Loaf. $143[\mathrm{r}] 60$

Com.f. 41 [r 72]

Pol.f. 153 [r, v. 453]

Pol.f. 148 [r, v. 25]

Can.f. 40 [39v 223]

Sol.f. 166 [v, I, v. 932]

Son.f. 3 [v 163]

Son.f. 4 [r 169]

Son.f. 12 [r 15]

Son.f. 5 [r 284]

Can.f. 44 [v 25]

Son.f. $31[\mathrm{v}]$

Can.f. 41 [r 72]

Son.f. 9 [r 174]

Letri.f. 76 [r 445] ¡oh claro honor* del freno ${ }^{104}$ mexicano!,

coronada la paz* de Octaviano ${ }^{105}$

de triunfos inmortales,

que ilustran* a los cielos de fanales,

luciente paga* de una breve Aurora,

donde, espumoso, ${ }^{*}$ redes exponiendo

se estremeció, tembló* dragón horrendo;

65 a vuestros descendientes* poca tierra, verá la gente* lo que España encierra, cuanto mar baña,* cuando Febo dora, que la que ilustra el cielo en luz,* segundos hará* multiplicarse, nacer, mundos.

70 Quédate aquí, canción, ${ }^{*}$ pues ya expira avena pastoral* mi tosca lira; después me oirán* del español Atlante de la Cerda inmortal* tan gran trofeo, que pretenda* la voz de algún deseo.

\section{6}

Segundo lugar

Alonso Ramírez de Vargas ${ }^{106}$

Con naval pompa* de inquieto lino, velero bosque* aun contra el viento armado, la prora diligente* en poca arena no sólo dirigió,* descaminado,

5 el príncipe troyano* peregrino, mas redújola ${ }^{107 *}$ entre una y otra almena, tocó las playas, $\operatorname{mas}^{108 *}$ fue de su pena
Son. f. 3 [r 163]

Pan.f. 182 [r, v. 96]

Loaf. 145 [r]

Loaf. 143 [r]

Pan.f. 182 [r, v. 78]

Ibidem

Can.f. 43 [r 256]

Ibidem

Son.f. 29 [v 319]

Loaf. 145 [r]

Son.f. 3 [v 163]

Can.f. 41 [r 72]

Ibidem

Can.f. 43 [r 256]

Son.f. 9 [r 136]

Ibidem
Can.f. 42 [r 16]

Son.f. 3 [r 163]

Sol.f. 169 [r, II, v. 49]

Sol.f. 169 [r, II, v. 50]

Com.f. 224 [v, v. 1225]

Sol.f. 169 [r, I, v. 51]

Son.f. 11 [r 42]
Son.f. 3 [r 163]

Sol.f. 188 [v, II, v. 21]

Sol.f. 188 [v 284]

Son.f. 9 [r 100]

Son.f. 7 [r 168]

Son.f. 8 [r 67]

Sol.f. 164 [r, $I$, v. 742$]$

${ }^{104}$ Supongo que "freno" en el sentido de autoridad a la que se somete el pueblo mexicano.

${ }^{105}$ Cayo Julio César Octaviano Augusto: considerado el primer y más importante emperador romano; gobernó durante 40 años; acabó con un siglo de guerras civiles y dio a Roma una era de paz.

${ }^{106}$ Reproduzco este centón en Tenorio (657-659).

${ }^{107}$ Como sucede frecuentemente en Góngora, reducir está como latinismo: reducere: traer de regreso, traer consigo: "[el pastor] los bueyes a su albergue reducía,/ pisando la dudosa luz del día" (Polifemo, vv. 71-72); "La prora diligente/ no sólo dirigió a la opuesta orilla,/ mas redujo la música barquilla..." (Soledad II, vv. 49-51).

${ }^{108}$ En la edición que se supone usan los concursantes, este verso (f. 11r), segundo del soneto que comienza "No destrozada nave en roca dura", se lee "tocó la playa más arrepentida", y así aparece en la edición que empleo de las Obras completas. Además de la trampita de hacer plural "la playa", tal vez ese más, adverbio de cantidad en el original, en el centón funcione 


\section{Centones gongorinos en Nueva España}

Sol.f. 155 [v, $I, \mathrm{v} .64]$

Son.f. 33 [r 355]

Pan.f. 183 [v, v. 197]

Pol.f. 153 [r, v. 432]

Pol.f. 151 [v, v. 341]

Pan.f. 182 [v, v. 113]

Sol.f. 174 [v, II, v. 21]

Sol.f. 188 [v, II, v. 128]

Sol.f. 170 [v, I, v. 378]

Sol.f. 159 [168v, $I$, v. 378]

Sol.f. 155 [v, I, v. 53]

Pan.f. 182 [r, v. 102]

Can.f. 42 [v 256]

Pan.f. 182 [r, v. 92]

Son. f. 13 [r 16]

Can.f. 52 [v 1]

Com.f. 197 [v, v. 1079]

Sol.f. $165[\mathrm{v}, I, \mathrm{v} .778]$

Son.f. 34 [r 387]

Can.f. 48 [v 293] término luminoso:

que, fuego él expirando, ${ }^{*}$ afectüoso

10 Delos, campos apenas* ha ofrecido, do halló reparo* agradecidamente, cuando de amor* admira, reverente, deidad que en isla* se venera culta, ${ }^{109}$ triunfando* del agua que la oculta

15 aun contra el* Orión humedecido; ${ }^{110}$ que ser quiso en* el mar sin cobardía al frigio, muro* y resistencia al día. ${ }^{111}$ Del mar siempre sonante,* más seguro, el margen pisó ameno* en tanto, donde

20 por este culto ${ }^{112}$ bien* $^{*}$ de un sol luciente el oráculo* dulce le responde con regalado son* al aire puro; lauro por premio* gradüadamente ofrece alegre* Dios omnipotente,

25 a su ardiente deseo, suma felicidad,* alto trofeo:

Edades ciento ahora* prorrogando
Sol.f. 171 [v, II, v. 239]

Pan.f. 187 [Is., v. 1695]

Sol.f. 176 [v, $I$, v. 646]

Can.f. 39 [r 223]

Sol.f. 171 [r, II, v. 199]

Sol.f. 171 [r, II, v. 196]

Son.f. 24 [r 218]

Son.f. 19 [r 140]

Sol.f.166 [v, I, v. 539]

Sol.f. $155[\mathrm{v}, I, \mathrm{v} .56]$

Pol.f. 149 [v, v. 177]

Can.f. 41 [v 146]

Pol.f. 150 [r, v. 181]

Oct.f. 53 [v 310$]$

Sol.f. 167 [v, I, v. 1024]

Com.f. 230 [v, v. 7]

Pol.f. 150 [v, v. 238]

Pan.f. 180 [r, v. 408]

mejor como conjunción adversativa: después del naufragio, Eneas, peregrino, descaminado ('perdido'), por fin toca tierra; esa llegada a playas extrañas (Cartago, como descubrirá después, donde le darán amparo) se convierte (aunque él, perdido y espantado aún no lo sepa) en el término feliz de su travesía.

109 "culta" aquí es participio del verbo latino colo: venerar; la expresión en Góngora (Soledad II, v. 199: “...albergues, donde la humildad contenta/ mora, y Pomona se venera culta") no es pleonástica (se trata de una alabanza a la horticultura del lugar); aquí sí tiene un valor enfático.

${ }^{110}$ Orión es la constelación de la lluvia.

${ }^{111}$ Este segundo hemistiquio "resistencia al día" se puede aclarar a partir del original gongorino: el cansado peregrino llega a un lugar donde "el fresco de los céfiros rüido,/ el denso de los árboles celaje,/ en duda ponen cuál mayor hacía/ guerra al calor o resistencia al día" (Soledad I, vv. 536-539); es decir, quién refrescaba más al peregrino, el aire de los céfiros o la resistencia que oponía el follaje a la luz del sol. La paráfrasis de esta primera estancia podría ser: después de un naufragio, el perdido ("descaminado") y peregrino Eneas (el "príncipe troyano") no sólo dirige su nave en poco espacio ("en poca arena"), sino que la regresa consigo hacia playa segura, en donde alcanza a entrever un palacio ("entre una y otra almena"); esa playa fue el final de su doloroso peregrinar. En ese lugar, Delos, que despedía, como ofreciendo afecto al peregrino, el calor de sus altares y hogares, encontró Eneas, agradecido, descanso. Ahí, desde lejos, todavía semi oculta por el agua, admiró con reverencia a la deidad que en la isla se veneraba. En medio del mar y de las tribulaciones de Eneas, Delos quiso ser el muro al que pudiera asirse el frigio, y cobijo ("resistencia al día") para su cansancio.

112 "culto": en el sentido de cultivado, procurado: el bien (beneficio) que Eneas se procura al buscar la ayuda divina (el oráculo). 


Can.f. $40[\mathrm{v} 72]$
Can.f. $40[\mathrm{v} 72]$
Pan.f. $147[\mathrm{v}, \mathrm{v} .23]$
Can.f. $40[\mathrm{v} 72]$
Sol.f. $177[\mathrm{v}, \mathrm{II}, \mathrm{v} .726]$
Son.f. $3[\mathrm{v} 163]$
Son.f. $3[\mathrm{v} 163]$
Son.f. $2[\mathrm{r} 25 \mathrm{l}]$
Son.f. $30[\mathrm{r} 333]$
Pan.f. $184[\mathrm{v}, \mathrm{v} .289]$
Son.f. $2[\mathrm{r} 25 \mathrm{l}]$
Com.f. $206[\mathrm{v}, \mathrm{v} .2210]$
Can.f. $52[\mathrm{r} 1]$
Can.f. $51[\mathrm{r} 416]$
Oct.f. $144[\mathrm{v}]$
Can.f. $39[\mathrm{r} 223]$
Son.f. $4[\mathrm{r} 169]$
Sol.f. $179[\mathrm{no}$ existe $]$
Son.f. $1[\mathrm{r} 266]$
Pan.f. $187[\mathrm{r}, \mathrm{v} .503]$
Pan.f. $181[\mathrm{v}, \mathrm{v} .55]$
Oct.f. $144[\mathrm{v}]$
Oct.f. $145[\mathrm{v}]$
Pan.f. $187[\mathrm{v}, \mathrm{v} .527]$
Sol.f. $159[\mathrm{v}, I, \mathrm{v} .393]$
Pol.f. $151[\mathrm{r}, \mathrm{v} .262]$

fía que en sangre de* Real venera

Madre dichosa,* ya que serlo espera,

30 Clarín, y de la Fama repetido, ilustrará* tu nombre esclarecido, fecunda Madre,* aljófares sudando, verá la gente* el último elemento multiplicarse imperios* ciento a ciento. ${ }^{113}$

35 No es voz* en oráculo profano, no a deidad fabulosa* consultada esta, pues, gloria* a la inmortal memoria, sino de la razón* edificada, que admira el cielo:* coro soberano

40 suénela* y del olvido haya victoria, monarca* concedido a mayor gloria. De tierra no oprimida, ofrece al gran Filipo, ${ }^{114 *}$ agradecida, de sucesión real* alta esperanza

45 esta divina* ya con verdad suma Delos, dos mundos, ${ }^{*}$ una y otra espuma; porque, celoso, ${ }^{115 *}$ a luz de este hemisferio le mereció* este altísimo Misterio el celo ardiente* y empuñar la lanza

50 Carlos, darte el valor,* alta reseña, mudo ejemplo* devotamente enseña. ${ }^{116}$ En esta, pues, fiándose* gloriosa corona inmóvil* del candor primero,
Can.f. 41 [v 146]

Can.f. 41 [v 146]

Pol.f. 148 [v, v. 92]

Son.f. 30 [r 312]

Pol.f. 150 [r, v. 188]

Can.f. 42 [r 165]

Sol.f. 179 [v, II, v. 895]

Son.f. 2 [r 251]

Son.f. 2 [r 251]

Sol.f. 160 [v, I, v. 479]

Son.f. 12 [v 99]

Com.f. $230[\mathrm{v}, \mathrm{v} .4]$

Son.f. 1 [v 39]

Son.f. 164 [v 449]

Pol.f. 150 [v, v. 227]

Son.f. 4 [r 169]

Ter. f. 55 [no existe]

Son.f. 1 [r 266]

Son. f. $38[\mathrm{v}]$

Son.f. 38 [v]

Can.f. 41 [v 146]

Can.f. 49 [v 78]

Ibidem

Pan.f. 185 [r, v. 313]

Pol.f. 148 [v, v. 88]

${ }^{113}$ Eneas pisó la orilla amena, la parte más segura del mar siempre sonante; ahí le habló dulcemente un oráculo; el Dios omnipotente ofreció a su ardiente deseo la suma felicidad, el más alto trofeo: le aseguró que, con el paso del tiempo ("Edades ciento ahora prorrogando"), en la sangre de real linaje de su esposa, que espera ser madre dichosa, el clarín de la Fama hará célebre su ilustre nombre, "aljófares sudando" la madre será fecunda; el mundo, entonces, verá multiplicarse sus imperios, ciento a ciento, hasta el fin del orbe ("el último elemento").

${ }^{114}$ Felipe IV.

115 "celoso": "se aplica también al demasiadamente cuidadoso y vigilante de lo que de algún modo le pertenece, sin permitir la menor cosa en contra" (Dicc. Aut., s. v. zELOSO).

${ }^{116}$ Eneas no escuchó la voz de un oráculo profano; la promesa de la gloria de la inmortalidad no es el resultado de la consulta a una deidad de fábula, sino a una deidad edificada en la razón, a una deidad que el cielo admira. Cántela, pues, el coro soberano y quede el olvido derrotado en este monarca destinado a grandes glorias. Esta tierra divina, Delos (Nueva España), no oprimida, sino agradecida, ofrece la esperanza de descendencia real, en dos mundos, a uno y otro lado del océano, porque Felipe IV, como todos los monarcas españoles, fue celoso en extender el misterio (de la Inmaculada) en este hemisferio. 


\section{Centones gongorinos en Nueva España}

Sol.f. 164 [v, $I$, v. 783]

Son.f. 4 [v 252]

Son. f. 29 [v 319$]$

Son.f. 27 [v 289]

Son.f. 27 [v 289]

Son.f. 2 [v 194]

Son.f. 4 [r 162]

Son.f. 4 [r 162]

Son.f. 2 [v 154]

Sol.f. 177 [v, I, v. 726]

Son.f. 16 [r 34]

Sol.f. 168 [r, $I, \mathrm{v} .1057]$

Son.f. 38 [v 359]

Can.f. 40 [v 146]

Son.f. 3 [v 163]

Can.f. 40 [r 223]

Can.f. 52 [r 1]

Loaf. $144[\mathrm{v}]$

Pan.f. 180 [r, v. 431]

Pan.f. 180 [r, 432]
Virgen tan bella,* inexpugnable muro,

oráculo en España* verdadero

en cuanto Febo dora, ${ }^{*}$ siempre hermosa,

de la tranquilidad pisa* seguro

la arena enjuta* o elemento impuro,

Príncipe glorïoso,

clarísimo Marqués, ${ }^{*}$ ¡oh digno esposo

60 de beldad soberana!,* dulce en ella

vea lograda* tu Casa esclarecida

fecunda madre* de laurel ceñida:

siendo tuya la voz, ${ }^{*}$ los triunfos cante

más firme Apolo* en cítara sonante

65 de cristiano valor* de amiga estrella, la salud pise el suelo* mexicano, coronada la paz* de Octaviano. ${ }^{117}$

Verás, canción,* al Príncipe excelente dándole lustre* en toda edad luciente

70 la piedad de su pecho, ${ }^{*}$ generosa; ¡oh cuánta le darán* en los mortales jurisdicción gloriosa* los anales! ${ }^{118}$
Sol.f. 155 [v, I, v. 55]

Son.f. 20 [v 221]

Son.f. 23 [v 219]

Son.f. 13 [r 13]

Pan.f. 183 [v, v. 378]

Son.f. 4 [r 169]

Pol.f. 149 [r, v. 99]

Son.f. 2 [r 179]

Ibidem

Oct.f. 146 [r]

Ibidem

Can.f. 41 [v 146]

Son.f. 3 [r 163]

Pan. f. 182 [r, v. 96]

Oct.f. 144 [r]

Son.f. 2 [r 251]

Pol.f. 150 [no existe]

Pan.f. 180 [r, v. 432]

Sol.f. $170[\mathrm{r}, I I, \mathrm{v} .143]$

Prescindiendo del valor artístico de estas composiciones, no podemos ignorar que, aunque excéntricas, son textos muy complejos y ricos, que, además, dan cuenta de la recepción de Góngora en Nueva España. El poeta centonista delimita severamente sus posibilidades lingüísticas, confinadas al campo verbal de la poesía que le sirve de

${ }^{117}$ Paráfrasis: 'Eneas, pues, acogiéndose a esta isla, corona inmóvil, siempre candorosa (blanca, sin mancha), en esta Virgen siempre hermosa, verdadero oráculo de España y de todo el orbe ("cuanto Febo dora"), pisó la tranquilidad de su arena seca ("enjuta": sin agua, libre de los peligros del mar) [no entiendo por qué llama a la arena "elemento impuro", ¿por ser una mezcla?]'. Hasta aquí la primera parte de la estancia; en el paso a la segunda, hay un brinco de la tercera persona ("fiándose", "pisa seguro") a la segunda persona en el apóstrofe al marqués de la Laguna: 'Príncipe glorioso, ilustrísimo marqués, digno esposo de esa beldad, que tu casa esclarecida vea lograda en ella una fecunda madre, ceñida de laurel; que, siendo de tu linaje ("siendo tuya la voz") el nuevo y más firme Apolo (el hijo) cante (continúe) los triunfos de tu casa con cristiana valentía; el bienestar ("la salud") llegue al suelo mexicano, coronado con la paz de Octaviano'. El Triunfo parténico reúne dos celebraciones a la Inmaculada, una de principios de 1682 y otra de 1683. Esta canción pertenece a la primera. Ahora, según el Diario de Robles, el primogénito de los marqueses de la Laguna nació el 5 de julio de 1683; así que para cuando Ramírez de Vargas compuso este centón, la virreina todavía no estaba embarazada, por eso el tono de esperanzada exaltación de una futura maternidad.

118 'Verás, canción dichosa, cómo todo el tiempo la generosa piedad de su pecho dará lustre al Príncipe excelente. ¡Oh cuánta jurisdicción gloriosa entre los mortales le darán los anales!' 
modelo; su propuesta artística, dentro de un género tan marcado, está en las decisiones que tome y en las elecciones que haga dentro de ese campo. Así, en estos centones gongorinos, lo que queda de Góngora son unidades, versos individuales, membra que constituyen una nueva armonía poética. De ahí que el estudio de estos poemas resulte importante para el análisis de la función de la alusión en general.

Evidentemente, la calidad de los centones no es la misma. La mayoría no pasa de ser sólo un ejercicio poético, "tejido" con oficio y nada más. Sin embargo, en mi opinión, los de Agustín de Salazar y Torres y de Alonso Ramírez de Vargas son los mejores: en sus composiciones, el modelo trasciende la mera función de proveedor de "retazos", y el quid de la estética gongorina (la construcción de conceptos) se cuela de manera imperceptible, llevado por los propios versos del cordobés, oficiosamente reconfigurados por los poetas novohispanos.

\section{Bibliografía}

Ausonio, Décimo Magno

Obras. Tomo 2. Traducción y notas de Antonio Alvar Ezquerra. Madrid: Gredos, 1990.

Opera omnia. Edición de R. P. H. Green. Oxford: Oxford University Press, 1999.

Carreira, Antonio

"Góngora y el canon poético", en Begoña López Bueno (directora). El canon poético en el siglo XVII. Sevilla: Grupo PASO/Universidad de Sevilla, 2010, 394-423.

\section{Certamen poético}

México: Viuda de Bernardo Calderón, 1654.

Conte, Gian Biagio

The Rhetoric of Imitation: Genre and Poetic Memory in Virgil and Other Latin Poets. Edited and with a foreword by Charles Segal. Ithaca and London: Cornell University Press, 1986.

Stealing the Club from Hercules. On Imitation in Latin Poetry. Berlin: De Gruyter, 2017.

Diccionario de Autoridades (1732)

Edición facsimilar. Madrid: Gredos, 1984.

Diego, Gerardo

Antología poética en honor de Góngora. Madrid: Revista de Occidente, 1927.

La estela de Góngora. Estudio preliminar de Juan Neira. Santander: Universidad de Cantabria, 2003.

Empresa métrica

México: Viuda de Bernardo Calderón, 1665. 
Estatua de la paz

México: José Bernardo de Hogal, 1724.

GaLlardo, Bartolomé José

Ensayo de una biblioteca española de libros raros y curiosos. Madrid: Imprenta y Fundición de Manuel Tello, 1889.

GóngORA, Luis de

Todas las obras de don Luis de Góngora. Edición de Gonzalo de Hoces. Madrid: Imprenta Real, 1654.

Obras completas. Edición de Antonio Carreira. Madrid: Fundación José Antonio Castro, 2000.

LAMAcchia, Rosa

"Dall'arte allusiva al centone", en Atene e Roma, número 3 (1958), 193-216.

“Centoni”, en Enciclopedia Virgiliana. Roma: Istituto dell'Enciclopedia Italiana, 1996, 733-737.

Méndez Plancarte, Alfonso

Poetas novohispanos. Segundo siglo (1621-1721). Tomo 2. México: Universidad Nacional Autónoma de México, 1945.

OkÁčová, Marie

"Centones: Recycled Art or the Embodiment of Absolute Intertextuality?", en Kakanien Revisited (2009), 1-5.

Oxford Latin Dictionary

New York: Oxford University Press, 1879.

Parra García, Luis

"Pervivencia del centón en el Renacimiento: Cento ex Virgilio Gallus de Lelio Capilupi", en Cuadernos de Filología Clásica. Estudios Latinos, número 16 (1999), 363-411.

Ponce Gárdenas, Jesús

"El oro del otoño: glosas a la poesía de Agustín de Salazar y Torres", en Criticón, números 103-104 (2008), 131-152.

Prieto Domínguez, Óscar

De alieno nostrum: el centón profano en el mundo griego. Salamanca: Universidad de Salamanca, 2010.

Robles, Antonio de

Diario de sucesos notables. Edición de Antonio Castro Leal. México: Porrúa, 1946.

Ros, Carlos

La Inmaculada y Sevilla. Sevilla: Castillejo, 1994. 
Salazar y Torres, Agustín de

Cýthara de Apolo. Primera parte. Madrid: Antonio González de Reyes, 1694.

Tenorio, Martha Lilia

Poesía novohispana. Antología. Presentación de Antonio Alatorre. México: El Colegio de México/Fundación para las Letras Mexicanas, 2010.

Triunfo parténico

México: Juan de Ribera, 1683.

Virgilio

Obras completas. Edición bilingüe. Traducción de Aurelio Espinosa Pólit. Madrid: Cátedra, 2003. 